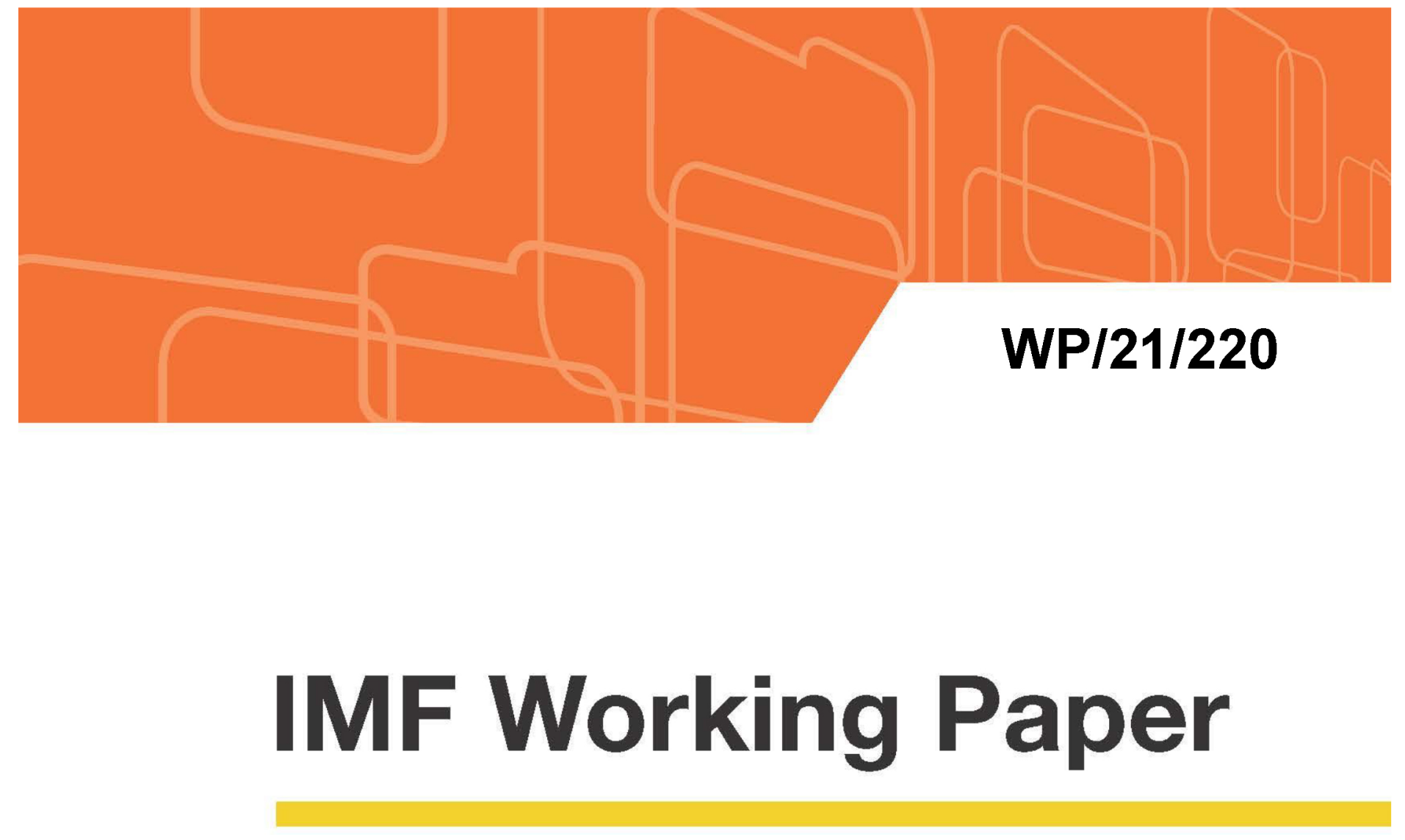

\title{
The Agricultural Exodus in the Philippines: Are Wage Differentials Driving the Process?
}

by Eugenio Cerutti and Yiliang Li

IMF Working Papers describe research in progress by the author(s) and are published to elicit comments and to encourage debate. The views expressed in IMF Working Papers are those of the author(s) and do not necessarily represent the views of the IMF, its Executive Board, or IMF management.

$$
\text { I N T E R N A T I O N A L M O N E T A R Y F U N D }
$$




\title{
IMF Working Paper
}

Asia and Pacific Department

\section{The Agricultural Exodus in the Philippines: Are Wage Differentials Driving the Process? ${ }^{1}$}

\section{Prepared by Eugenio Cerutti ${ }^{2}$ and Yiliang $\mathbf{L i}^{3}$}

Authorized for distribution by Thomas F. Helbling

August 2021

IMF Working Papers describe research in progress by the author(s) and are published to elicit comments and to encourage debate. The views expressed in IMF Working Papers are those of the author(s) and do not necessarily represent the views of the IMF, its Executive Board, or IMF management.

\begin{abstract}
Lagging labor reallocations outside agriculture amid sustained low agricultural productivity have been a key feature in the Philippines over the past 15 years. An analysis of the labor adjustments in and out of agriculture shows that a variety of factors have influenced this process. We find that the widening of wage differentials with non-agricultural sectors, improvements in labor market efficiency, and better transport infrastructure are largely associated with growing outflows of labor from agriculture, whilst the lack of post-primary education and the presence of agricultural clusters hinder such outflows. In contrast to the traditional view that agricultural employment outflows are largely driven by productivity differences and wage differentials, our results emphasize the roles of education as well as transport infrastructure in facilitating labor reallocations from agriculture to non-agriculture.
\end{abstract}

JEL Classification Numbers: E24, J24, J43, J64

Keywords: Agricultural employment, search and matching, wage differentials, labor market efficiency, transport infrastructure, education, economic significance

Author's E-Mail Address: ecerutti@imf.org; yiliang.li@economics.ox.ac.uk

\footnotetext{
${ }^{1}$ We thank Petr Sedláček, Bo Hyun Chang, Minsuk Kim, Thomas Helbling, Yongzheng Yang, Ervin Prifti, Andrea Pescatori, and participants at the Philippine Institute for Development Studies (PIDS) Virtual Research Workshop and IMF APD Seminar. All errors are ours. The opinions expressed herein are solely the responsibility of the authors and should not be interpreted as reflecting those of the IMF, its Executive Board, or IMF management.

2 International Monetary Fund, Asia and Pacific Department.

${ }^{3}$ University of Oxford, Department of Economics.
} 
I. Introduction.

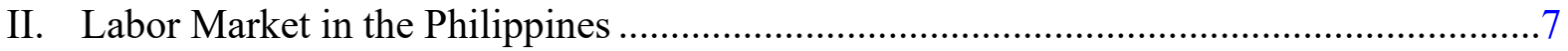

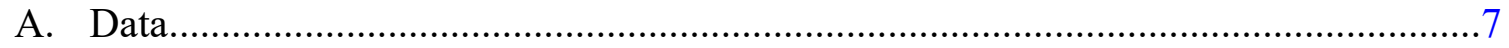

B. Time Series Trends of $E N$ and $N E$ Rates.............................................................

C. 'Push' and 'Pull' Drivers of the Intersectoral Labor Reallocations ..........................11

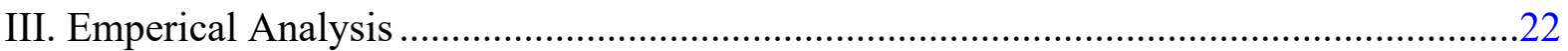

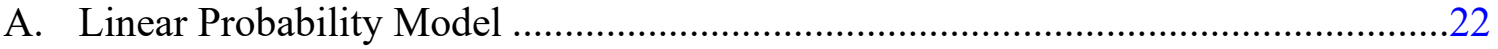

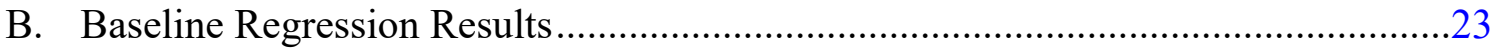

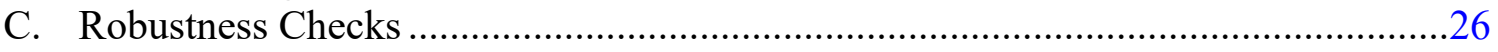

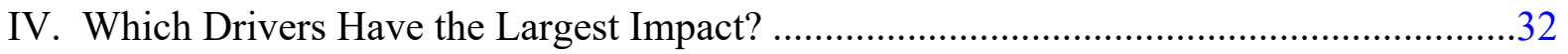

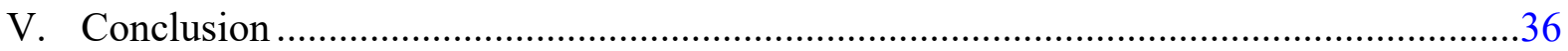

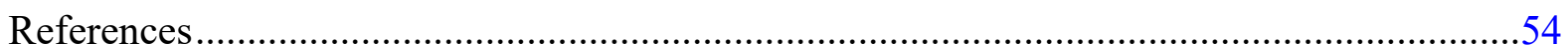

Figures

1. Agriculture Performance in Selected ASEAN Countries .................................................4

2. Labor Market Composition.......................................................................................9

3. Time Series Trends of the Labor Market Transition Rates .........................................10

4. Job Separation and Creation in the Agricultural Labor Market ....................................10

5. The Influence of Higher Non-Agricultural Productivity on Job Separation

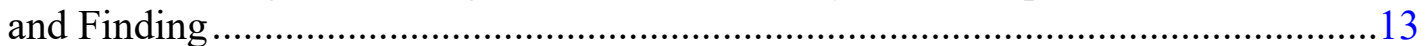

6. The Influence of Lower Agricutural Productivity on Job Separation and Finding ..........14

7. The Influence of Better Matching in Agriculture on Job Separation and Finding ...........15

8. The Influence of Lower Flow Outside Value for Agricultural Workers on Job

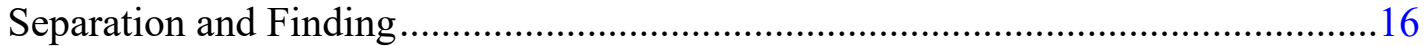

9. The Influence of Weaker Bargaining of Agricutural Workers on Job Separation

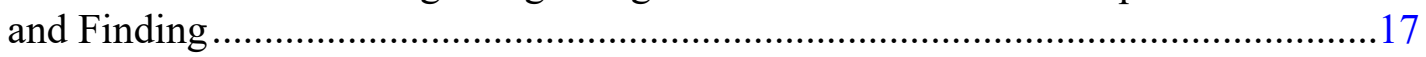

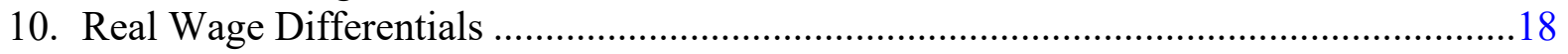

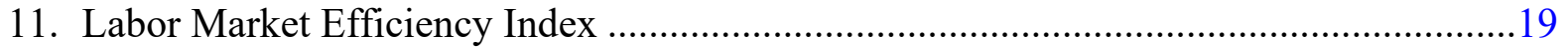

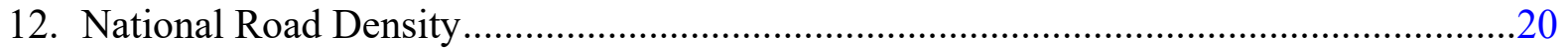

13. Share of Employed Workers with at Least High School Education...............................21

14. Regional Share of Total Palay and Corn Production...................................................22

15. Within-Region and Cross-Region Real Wage Differentials.........................................26

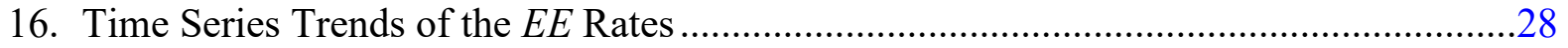

17. Average Share of Employed Workers with at Least High School Education,

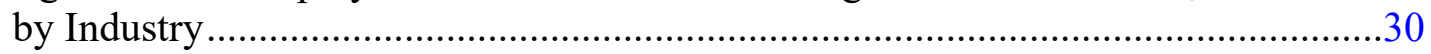

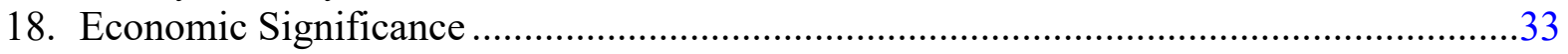

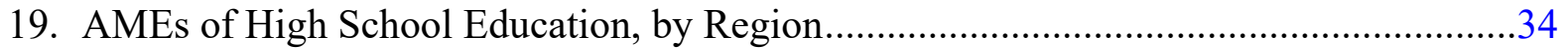

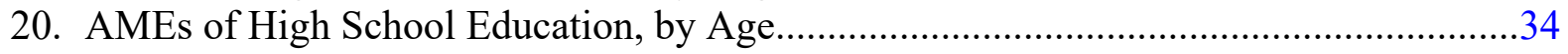

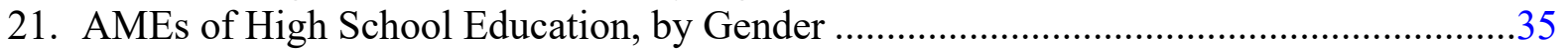


22. AMEs of Road Density, by Region

Tables

1. AMEs in the Baseline LPM .24

2. AMEs in the LPM with Cross-Region Real Wage Differentials....................................27

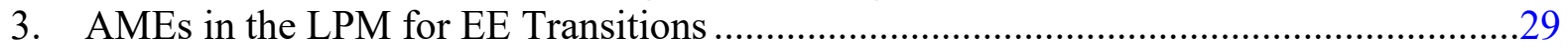

4. AMEs in the LPM for Transitions from Agriculture to Other Low-Skilled Industries....31

\section{Appendices}

I. Theoretical Model...

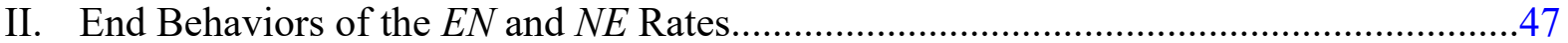

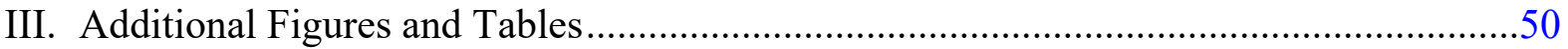




\section{INTRODUCTION}

Sustained low productivity in the agricultural sector as well as lagging labor reallocations have been at the center of discussion for decades in the Philippines (e.g., Qian et al. (2018), Briones (2017b), and Teruel and Kuroda (2005)). As illustrated in Figures 1a and 1b, the Philippines' agricultural sector has underperformed its regional peers in terms of productivity growth, even though its agricultural employment has been shrinking at a similar pace to the other countries over the past 15 years. Conventional wisdom (e.g., Felipe et al. (2014) for evidence in China, McCaig and Pavcnik (2013) for evidence in Vietnam, and McMillan and Rodrik (2011) for evidence in Asia, Latin America, and Africa) suggests that low agricultural productivity translates to large wage differentials with other sectors, and drives the employment outflows from agriculture to non-agriculture. ${ }^{1}$ Yet, studies have also shown that other social and economic factors (e.g., infrastructure as in Llanto (2012), land reform as in Adamopoulos and Restuccia (2020) and Koirala et al. (2016)) influence the agricultural worker's labor market behaviors, and therefore determine the pace of structural transformation. In light of these arguments, we aim to answer the following question: what is driving the shrinkage of agricultural employment in the Philippines? Wage differentials or other factors?

Figure 1: Agricultural performance in selected ASEAN countries

(a) Agricultural TFP

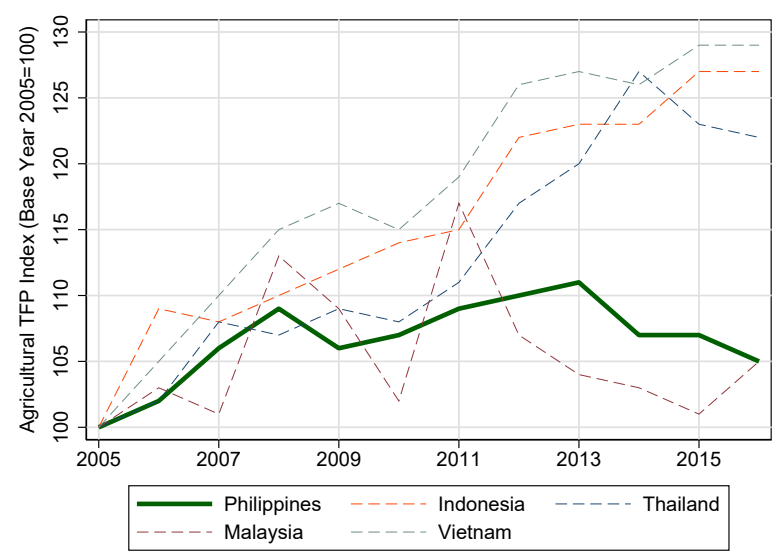

(b) Agricultural employment

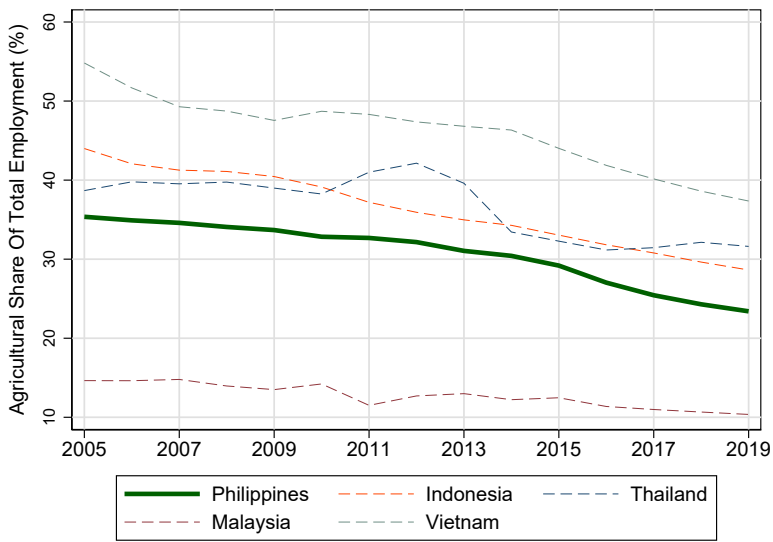

Notes: (1) for agricultural TFP, the data source is 2005-2016 Agricultural Total Factor Productivity Growth Indices for Individual Countries, US Department of Agriculture. For description of methodology, see Fuglie (2015) and Fuglie (2012); (2) for agricultural employment shares, the data source is the ILOSTAT database, International Labour Organization.

To understand the evolution that takes place in the Philippines' labor market, we take advantage

\footnotetext{
${ }^{1}$ This proposition can also be found in the structural transformation literature, for instance, Herrendorf et al. (2014).
} 
of the Philippines Labor Force Survey (LFS) and show empirically that the agricultural exodus in the Philippines is a flow process from agriculture to non-agriculture, but with an intermediate step where workers are either unemployed or non-participating. In this context, we find that the job separation rate in the agricultural sector has been on an increasing trend over the last 15 years, whilst the agricultural job finding rate has remained relatively constant. In contrast, the job separation rate in the non-agricultural sector has remained stable, whereas the nonagricultural job finding rate has soared. These dynamics suggest that the shrinking agricultural employment in the Philippines can be largely attributed to increasing job separation in agriculture and greater job finding in non-agriculture. Following this process across 17 administrative regions in the Philippines during 2005 to 2019, we take a novel two-step approach. Firstly, we construct a tractable equilibrium labor search and matching model featuring two types of industries, agriculture and non-agriculture, in order to study how changes in economic and institutional factors interact with various labor market decisions, including job separation and creation. We show analytically that, at the partial equilibrium of the agricultural labor market, the worker's behaviors are captured by the interactions between a positively-sloped job separation curve and a negatively-sloped job creation curve. We further illustrate that 'push' and 'pull' factors - those reflecting the incentives for workers to leave or remain in agriculture respectively - result in shifts of the job separation and creation curves, and thus lead to variations in the job separation and finding rates in the agricultural industry. In the next step, following the model predictions which serve to discipline our empirical analysis, we propose and analyze whether some key available 'push' and 'pull' factors are behind the observed evolution of the job separation and finding rates in the Philippines. In addition to real wage differentials across sectors, we gather information on labor market efficiency, both national and regional road density as a proxy for the evolution of infrastructure across time and regions, individual's high school and/or college education experience as a proxy for human capital development, and each administrative region's share in total palay and corn production as a proxy for agricultural clusters.

By regressing each of the labor market transition rates on the proposed factors, we find that they statistically help to explain the observed variations in the job separation and finding rates for agricultural and non-agricultural workers. We then show that sustained low productivity in agriculture translates to widening wage differentials, and thus seems to facilitate agricultural workers to separate more from their current jobs and direct their search effort elsewhere; such motives become especially prominent when labor market efficiency is improving in the non-agricultural sectors and transport infrastructure is upgraded, as agricultural workers can switch industries more freely. On the other hand, in terms of the effects from the 'pull' factors, the lack of sufficient education limits the ability of agricultural workers to transition into non-agricultural jobs, and essentially drags them back to agricultural employment due to fewer outside options; at the 
same time, the difficulty of switching out of the agricultural sector is also heightened when the region's economy is more dominated by agriculture. These results are statistically robust to considering cross-region real wage differentials, job-to-job transitions, as well as job separations and findings in the low-skilled non-agricultural industries, among others.

The results support that not only do increasing wage differentials affect the employment outflows from agriculture to non-agriculture, but other economic and institutional factors also play an important role in such transitions. Moreover, we find that contrary to the traditional view, in spite of the statistical significance, increasing real wage differentials do not contribute much to the agricultural exodus in the Philippines. Instead, measures related to enhancing the worker's ability to freely switch industries are both statistically and economically significant in explaining the observed developments in labor market transition rates. Specifically, high school education can add significantly more to the exodus through raising agricultural worker's job separation margin substantially. ${ }^{2}$ Building on that, when college education is undertaken, employment outflows from agriculture to non-agriculture could be further amplified because workers can now find and hold on to non-agricultural jobs more easily. Furthermore, improving transport also plays a more economically significant role in driving the agricultural exodus, as not only does higher road density reduce job finding in agriculture by a wide margin, but also it boosts job finding in non-agriculture significantly.

This paper makes two contributions to the literature. To the best of our knowledge, this paper is the first to estimate time series trends of the labor market transition rates in the Philippines and simultaneously examine the determinants through which changes in the transition rates give rise to shrinking employment in agriculture. Previous research largely focuses on whether a certain economic or demographic factor affects agricultural employment directly. We argue that this approach is too holistic as it ignores the important labor market transitions between the pools of employment and non-employment which underlie the employment outflows from agriculture to non-agriculture. In addition, this paper offers an assessment on the importance of each identified 'push' or 'pull' factor as a potential driving force of the agricultural exodus. We apply both the empirical assessment of economic significance and structural approach (embedded in the theoretical model) to illustrate the vital importance of providing channels/means to agricultural workers to facilitate their intersectoral reallocations.

These considerations are important not only for improving the performance of the agricultural sector in the Philippines, but also for lowering the scarring effects of the COVID-19 shock through more efficient intersectoral labor reallocations. Our results highlight the need to maintain effi-

\footnotetext{
${ }^{2}$ This is the case even when we compare it to the effect on job separation margin in low-skilled non-agricultural industries. See the third robustness check in Section $\mathrm{C}$ for details.
} 
cient labor markets and increase investment in education and transport infrastructure, as a com-

plement to finishing land reform measures that cannot be captured directly in our empirical study. As agriculture weakens and economies develop, a well-functioning labor market is crucial in reducing rural poverty and rural-urban income disparities, and policies can be developed in this regard to ensure effective preparedness of those who choose to leave agriculture. In addition, since a wider coverage of high school education proves sufficient to speed up labor reallocations from agriculture to non-agriculture, policymakers should pay more attention to promoting education and upgrading the skills of agricultural workers, especially those residing in regions with low education attainment and that could potentially benefit the most from education (e.g., the young and female). In addition, infrastructure investment could be further expanded since it also assists employment outflows from agriculture to non-agriculture.

The rest of this paper is organized as follows. Section II is devoted to establishing the facts of the labor market in the Philippines, including time series trends of the job separation and finding rates. Section III presents the baseline empirical results, identifies the relevant 'push' and 'pull' factors in explaining the observed developments in labor market transition rates, and performs robustness checks to support our main empirical findings. Section IV studies the relative importance of each identified factor and details our policy suggestions. Section V concludes. The Appendices contain additional model details, analytical results, robustness checks, and additional figures and tables.

\section{LABOR MARKET IN THE PHILIPPINES}

In this section, we document three aspects of the Philippines' labor market: firstly, we present the Labor Force Survey data; secondly, taking a stock-flow approach, we estimate time series trends of the job separation rate (or Employment to Non-employment rate, $E N$ ) and job finding rate (or Non-employment to Employment rate, $N E$ ) in both agricultural and non-agricultural sectors; and finally, we propose a theoretical framework and identify the evolution of some empirically available 'push' and 'pull' factors in affecting the agricultural worker's labor market behaviors.

\section{A. Data}

One of the main objectives of this paper is to examine the underlying reasons for the shift in employment from the agricultural to non-agricultural sectors. This is possible by using panel data that track each worker's labor market status. Therefore, we apply the Philippines Labor Force Survey (LFS) Microdata Public Use Files. The LFS tracks a nationally-representative sample of the Philippines' inhabitants, and the cleaned dataset contains in total nearly 11.4 million quarterindividual observations, spanning from 2005Q2 to 2019Q4 and covering 17 administrative re- 
gions. Since its initiation in the 1980s, the LFS has undergone several structural changes and the definition of employment/unemployment/non-participation varied significantly across different years. Considering this, we decide to restrict the sample from 2005Q2 to 2019Q4 because (1) the identification of discouraged workers is only available from 2005Q2 onward when the inquiries that were deemed necessary to adequately capture the availability criterion and to reflect the reference period started to be incorporated; and (2) the questions related to worker's employment in the past quarter are only available from 2005Q2 onward; these questions are critical in the sense that they allow us to capture changes in employment status and industry in which the worker is employed. The dataset contains in total 21 variables, ranging from the worker's basic demographic characteristics to his/her employment status and daily pay.

We use the LFS because of its three unique features: it is (1) a longitudinal dataset with (2) quarterly data that (3) records each individual's labor market behaviors. These three features are necessary to identify what factors are driving the employment outflows from agriculture to nonagriculture. We need labor market panel data in order to observe the outcomes of the worker's job search, and the data also need to be of sufficiently high frequency in order for us to construct statistically meaningful job separation and finding rates and to avoid the time aggregation bias (e.g., Shimer (2012), Elsby et al. (2009), and references therein). However, despite the richness and usefulness of information in the LFS, it is a micro panel with large $N$ but small $T$ : even though we observe the changes in labor market behaviors by individuals between two adjacent quarters, we are unable to uniquely identify each individual across quarters due to the lack of individual and geographic ID variables. In addition, the survey question in the LFS asking each worker's employment status in the past quarter does not distinguish unemployment from nonparticipation. This leads us to group the unemployed with non-participants and study the labor market behaviors by the non-employed in general. This limitation as unemployment and nonparticipation are distinct labor market statuses over the business cycles is not critical in emerging economies. Specifically, Elsby and Shapiro (2012) and Juhn et al. $(1991,2002)$ argue that the boundary is blurred over the long-run. At low frequencies, the unemployed resemble nonparticipants because they have relatively long spells of joblessness and minimal employment opportunities. Moreover, Bosch (2016) illustrates that the lack of unemployment insurance in emerging economies gives rise to workers who experience long spells of unemployment losing momentum to continue to search, essentially behaving as non-participants in the long-run.

We restrict our sample to individuals with age of 15 to 64, and employed workers excluding public administration, defense, compulsory social security, and extra-territorial organizations and bodies. $^{3}$ We exclude individuals below the age of 15 because according to the Labor Code of the

\footnotetext{
${ }^{3}$ Since 2012, the Philippine Standard Industrial Classification (PSIC) has adopted the 2009 standard which
} 
Philippines Implementing Rules and Regulations, even though the minimum age for employment is 18 years old, persons of age 15 to 18 can be employed given that they work in non-hazardous environments. On the other hand, we keep individuals above the age of 60 but below 65 even though the official retirement age in the Philippines is set at 60. This is because the retirement age for an employee depends specifically on the employment contract. Only if there were no existing retirement plan or agreement for the employee might he/she retire at the age of 60 , given that he/she has served the employer for 5 years, and shall be given a retirement pay of at least half a month's salary for every year of service (6 months of work given is considered as 1 whole year for the retirement pay). In addition, by examining the LFS data, we find that there are on average $3.8 \%$ of employed workers each quarter that have an age between 60 and 64, therefore representing a non-negligible share of employment in the Philippines. Lastly, we exclude individuals working in public administration, defense, compulsory social security, and extra-territorial organizations and bodies so as to restrict our attention to the employment/non-employment dynamics in the private sector labor market.

\section{B. Time Series Trends of the $E N$ and $N E$ Rates}

Figure 2: Labor market composition

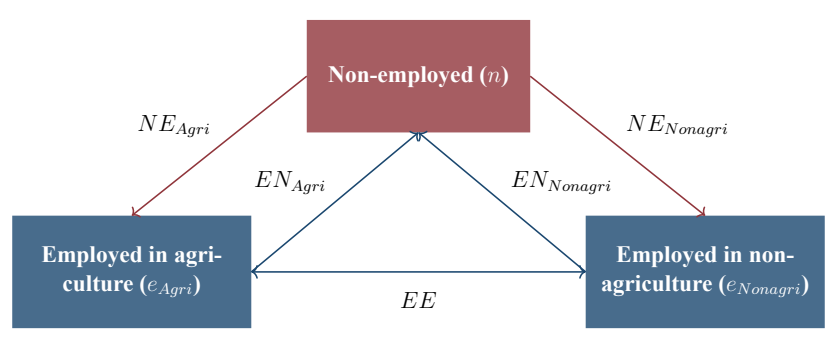

Changes in employment are often driven by variations in the labor market transition rates. Therefore, in order to understand why the agricultural employment share has been declining in the Philippines during the past 15 years, we dissect the labor market and take a stock-flow approach. As illustrated in Figure 2, we see that while the stock of employment in agriculture $e_{\text {Agri }}$ is directly affected by its outflow and inflow rates, $E N_{A g r i}$ and $N E_{A g r i}$, the transition rates in nonagriculture, $E N_{N o n a g r i}$ and $N E_{\text {Nonagri }}$, also have an indirect impact through altering the compo-

changed significantly from the 1994 PSIC. Using the crosswalks, we create 16 major industry codes that are consistent over time. The classification is relatively coarse, but creating consistent codes necessarily requires aggregation of underlying two-digit codes into fairly broad categories such as those used in this paper. The industries are: agriculture, forestry, and fishing; mining and quarrying; manufacturing; electricity, gas, and water supply; construction; wholesale and retail trade; repair of motor vehicles, motorcycles, and personal and household goods; hotels and restaurants; transport, storage and communications; financial intermediation; real estate, renting, and business activities; public administration, defense, and compulsory social security; education; health and social work; other community, social, and personal service activities; activities of private households as employers and undifferentiated production activities of private households; and extra-territorial organizations and bodies. 
sition of the non-employment pool. Note that in practice there are job-to-job $(E E)$ transitions, through which workers switch industries without experiencing a non-employment spell in between. However, we do not model or include in the empirical baseline such transitions because agricultural (non-agricultural) workers only switch to non-agricultural (agricultural) employment through job-to-job transitions with an average probability of $2.4 \%(0.9 \%)$ during the sample period.

After establishing the links between agricultural employment and the corresponding labor market transition rates, we define the samples used to calculate the $E N$ and $N E$ rates. For the $E N$ rates, the underlying sample contains matched records that start with employed in the past quarter; the dependent variable takes 1 when an $E N$ transition occurs and 0 when the worker remains employed. Likewise, the sample for $N E$ rates consists of those who are non-employed in the past quarter; the variable takes 1 if the worker is employed in the survey quarter and 0 otherwise. To calculate the $E N$ rates ( $N E$ rates) for agricultural and non-agricultural workers respectively, we further classify each sample based on whether the worker is employed in the agricultural sector before non-employment (after non-employment).

Lastly, to visualize the long-run trend of each labor market transition rate, we firstly calculate the weighted average $E N$ and $N E$ rates based on the final person weights provided for each survey quarter, and then apply the Hodrick-Prescott Filter to extract the trend component of each series; the smoothing parameter is set to 1600 .

Figure 3: Time series trends of the labor market transition rates

(a) $E N$ rates

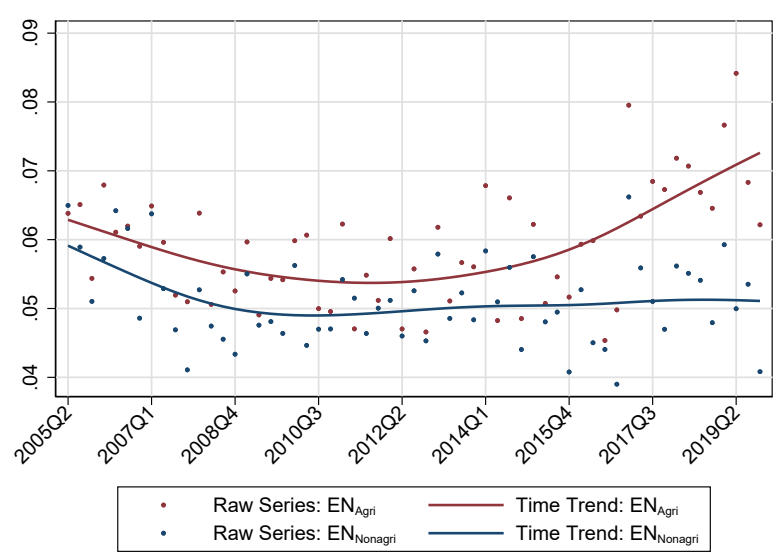

(b) $N E$ rates

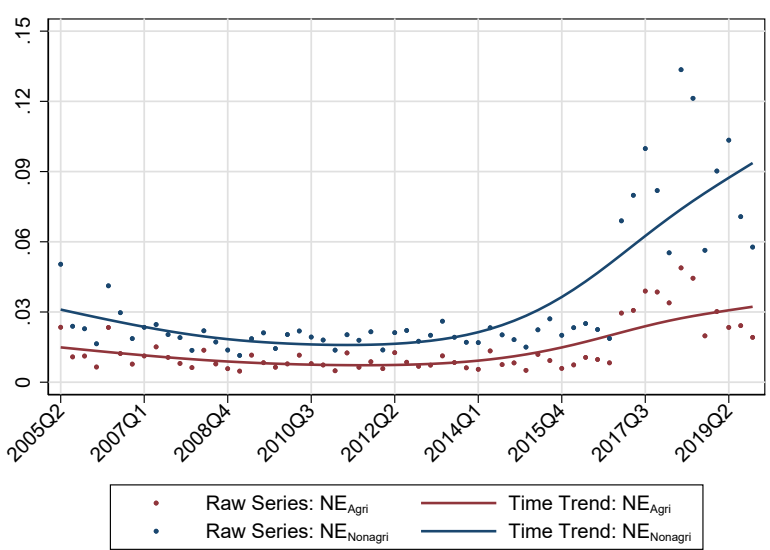

Source: Labor Force Survey, Philippine Statistics Authority. The trends are estimated using the Hodrick-Prescott Filter with smoothing parameter of 1600. 


\section{EN Rates}

Figure 3a plots time trends and unadjusted raw series of the $E N$ rates for agricultural and nonagricultural workers respectively. The unadjusted raw series are average quarterly means, weighted by the LFS final person weights. By comparing the trends, we can clearly see that in levels, the $E N$ rate is on average higher for agricultural workers, and the difference is widening in more recent years. In the early sample, both the $E N$ rates for agricultural and non-agricultural workers have been declining, while in the latter half, the $E N$ rate for agricultural workers rises sharply and overtakes its 2005 level, reaching $7.3 \%$ at the end of the sample; during the same time, the $E N$ rate for non-agricultural workers remains relatively stable.

\section{$N E$ Rates}

Figure $3 \mathrm{~b}$ plots time trends and unadjusted raw series of the $N E$ rates in agriculture and nonagriculture respectively. The $N E$ rate is on average lower in the agricultural sector, and the difference is also increasing more recently. Both $N E$ rates remain low before 2016 when they start climbing; the rise of $N E$ rate in the non-agricultural sector is significantly larger than the one in agriculture.

In summary, by examining time series trends of the $E N$ and $N E$ rates, we conclude that the agricultural exodus in the Philippines is a flow process from agriculture to non-agriculture, but with an intermediate step where workers are either unemployed or non-participating; it is mostly driven by the increasing outflows from agricultural employment to non-employment as well as larger inflows from non-employment to non-agricultural employment.

\section{C. 'Push' and 'Pull' Drivers of the Intersectoral Labor Reallocations}

In the previous subsection we show that there exist drastic differences in the labor market transition rates for agricultural and non-agricultural workers, and the disparity has widened in recent years. In order to understand how the $E N$ and $N E$ rates are shaped, and explore the extent to which the social and economic reforms in the Philippines affect an individual's job separation and finding probabilities, we follow the theoretical foundation and propose within its discipline two specific sets of factors, with 'push' factors capturing incentives for workers to leave agriculture and 'pull' factors capturing incentives for workers to remain in agriculture. Subsequently, we assess the importance of each proposed factor in the context of the Philippines. 


\section{Theoretical Foundation}

We start with a theoretical approach by constructing a model of the labor market. Then, we use the model to study the influence of 'push' and 'pull' factors in general on job separation and finding in the agricultural sector in a systematic manner. Specifically, to capture the empirical observation that job openings and job seekers simultaneously exist, we build a two-market random search model in the spirit of the seminal work by Mortensen and Pissarides (1994), where labor market frictions prevent job openings and job seekers from perfectly matching up. The model accounts for the job finding, separation, and industry switching behaviors by workers in both agriculture and non-agriculture while remaining analytically tractable. ${ }^{4}$

Figure 4: Job separation and creation in the agricultural labor market

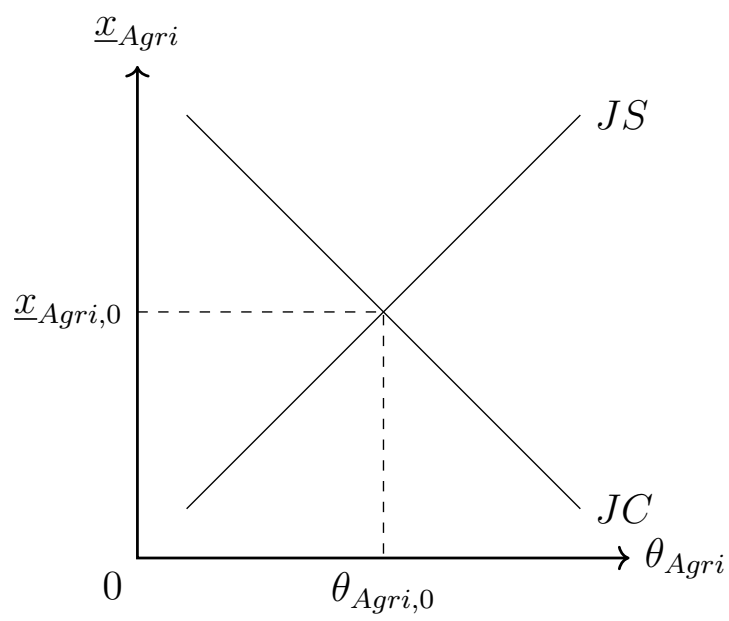

Notes: (1) $\underline{x}_{A g r i}, \theta_{\text {Agri }}$ stand for reservation productivity and labor market tightness in the agricultural labor market respectively; (2) $\left(\underline{x}_{\text {Agri, }}, \theta_{\text {Agri, }, 0}\right)$ depicts the partial equilibrium by the intersection of the JS and JC curves; and (3) for graphical representation, we only plot the JS and JC curves as straight lines and neglect the changes in slopes at different combinations of $\left(\underline{x}_{\text {Agri }}, \theta_{\text {Agri }}\right)$.

Through the lens of the model, as in Figure 4, we show that there exist a positively-sloped job separation $(J S)$ curve and a negatively-sloped job creation $(J C)$ curve in the plane containing reservation productivity and labor market tightness in agriculture. Intuitively, reservation productivity in the labor market refers to the cutoff productivity below (above) which workers and firms choose to sever (continue) their employment relationship, while labor market tightness measures the balance between the demand for, and the supply of, labor - the tighter the labor market is, the higher the demand for labor will be. The positive slope of the $J S$ curve captures a notion that higher demand for labor (as measured by larger $\theta$ ) implies greater outside option value for workers, hence leading to more job offers which do not promise sufficiently high returns being

\footnotetext{
${ }^{4}$ Details of the model can be accessed in Appendix I.
} 
declined. ${ }^{5}$ In terms of the negative slope of the $J C$ curve, it captures exactly the opposite: higher demand for labor implies smaller outside option value for firms as it becomes more difficult to fill a vacancy. In consequence, firms lower their reservation productivity to attract more labor. Lastly, the intersection of the two curves marks the partial equilibrium in the agricultural labor market, and any shift in the $J S$ or $J C$ curve due to changes in labor market conditions will result in corresponding changes in the underlying endogenous variables, and thus affect the equilibrium job separation and finding rates in the agricultural sector.

Figure 5: The influence of higher non-agricultural productivity on job separation and finding

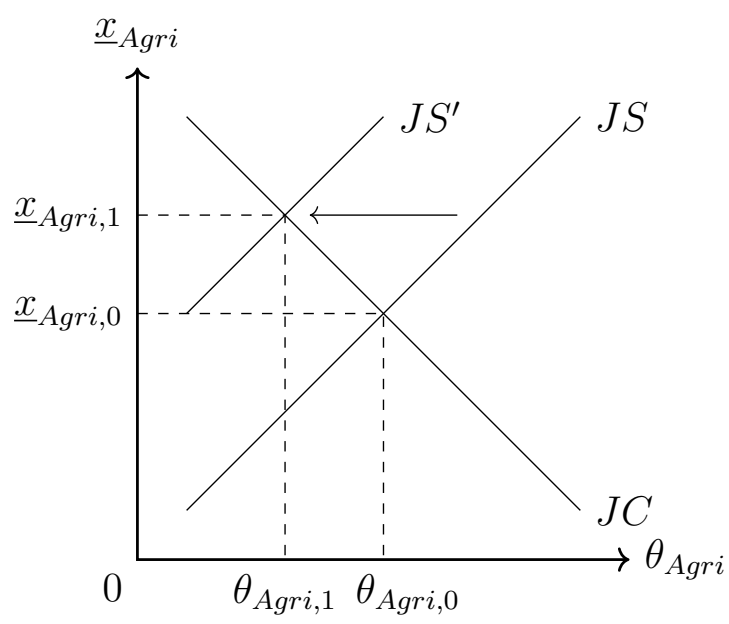

Notes: (1) $J S^{\prime}$ represents the shifted job separation curve following an exogenous increase in the non-agricultural productivity; (2) the intersection between the $J S^{\prime}$ and $J C$ curves represents the new (partial) equilibrium in the agricultural labor market, featuring $\left(\underline{x}_{A g r i, 1}, \theta_{\text {Agri, } 1}\right)$.

In terms of the 'push' factors, let's first consider an exogenous increase in the non-agricultural productivity such that the outside option for workers switching from agriculture to non-agriculture becomes more favorable. This is captured in the model with a leftward shift of the $J S$ curve to $J S^{\prime}$ as depicted in Figure 5. Assuming all else remains constant, at the new equilibrium where the $J S^{\prime}$ and $J C$ curves intersect, the reservation productivity increases whilst the agricultural labor market tightness drops. Since the separation rate in agriculture can be shown to monotonically increase in the reservation productivity, such changes imply greater job separation in agriculture in equilibrium; since the outside option value for agricultural workers increases as a result of the higher non-agricultural productivity, they become more 'picky' about job offers and decline more often. In terms of the job finding rate, it is monotonically increasing in agricultural labor market tightness and decreasing in reservation productivity. Therefore, the confluence of

\footnotetext{
${ }^{5}$ In the model, when bargaining over an employment relationship, the outside option of the worker is to either remain unmatched in the current industry or to switch to the other industry, whilst the outside option of the firm is to remain unmatched and wait for another worker.
} 
higher reservation productivity and lower tightness in equilibrium implies a lower job finding rate in agriculture; not only do agricultural workers decline offers more often, but also they face more difficulties in meeting a potential employer. In reality, such a productivity difference often manifests itself through widening wage differentials, therefore incentivizing agricultural workers to move away from their land and search for non-agricultural jobs instead.

Similar dynamics can arise from an exogenous increase in the flow outside value for non-agricultural workers or an exogenous increase in the matching efficiency in the non-agricultural industry, as they both behave to raise the outside option value faced by agricultural workers. ${ }^{6}$ It is also noted that the increasing productivity difference between agriculture and non-agriculture may result from lower agricultural productivity instead (recall Figure 1a), which in certain scenarios (see Figure 6 for an illustration) will lead to both the $J S$ and $J C$ curves shifting to the left, and yield similar outcomes to those with only the $J S$ curve shifting to the left.

Figure 6: The influence of lower agricultural productivity on job separation and finding

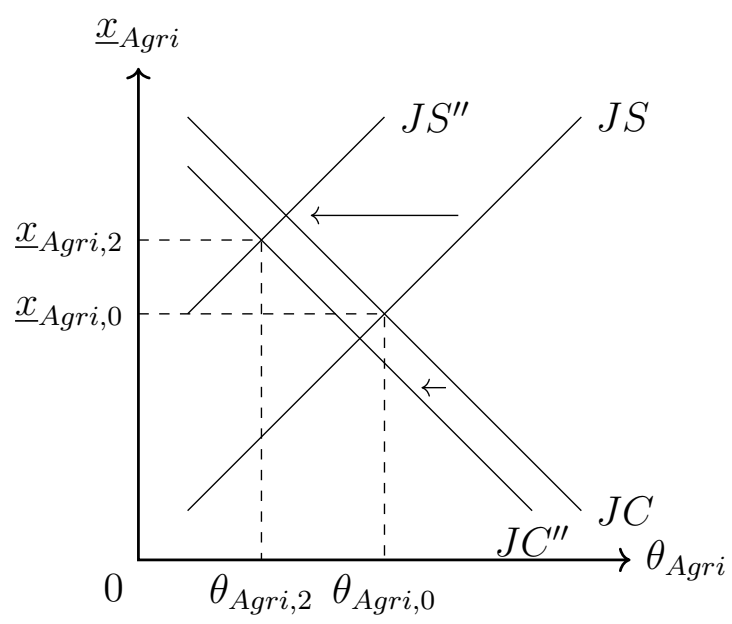

Notes: (1) $J S^{\prime \prime}$ and $J C^{\prime \prime}$ represent the shifted job separation and creation curves following an exogenous decrease in the agricultural productivity; (2) the intersection between the $J S^{\prime \prime}$ and $J C^{\prime \prime}$ curves represents the new (partial) equilibrium in the agricultural labor market, featuring $\left(\underline{x}_{\text {Agri,2 }}, \theta_{\text {Agri, }, 2}\right)$.

In addition to the aforementioned 'push' factors, a boost to matching efficiency in the agricultural industry may also lead to significant employment outflows from agriculture, even though the exact mechanism through which the outflows take place varies from the previous ones. Specifically, it triggers not only a leftward shift of the $J S$ curve, but also a rightward shift of the $J C$ curve. The intuition is that the boost to matching efficiency in the agricultural industry not only enhances the outside option for its workers (as they can find jobs more easily), but also improves

\footnotetext{
${ }^{6}$ For reference, the flow outside value refers to the per-period utility that the worker gets during nonemployment, e.g., unemployment benefits and leisure.
} 
the ability of firms in filling their vacancies and hence encourages them to create more agricultural jobs. Graphically, in Figure 7, assuming that the shift in the $J C$ curve is relatively small, at the new equilibrium where $J S^{\prime \prime \prime}$ and $J C^{\prime \prime \prime}$ curves intersect, the reservation productivity increases whilst the agricultural labor market tightness falls. This leads to similar outcomes as in the other cases, namely, greater job separation but lower job finding probabilities in the agricultural industry. Therefore, given the above model predictions, it is expected that better-functioning labor markets and increasing measures to boost matching efficiency in both agriculture and nonagriculture (e.g., improved transport infrastructure) would serve to promote agricultural employment outflows - proxies of these 'push' factors will be formally tested later in the empirical section.

Figure 7: The influence of better matching in agriculture on job separation and finding

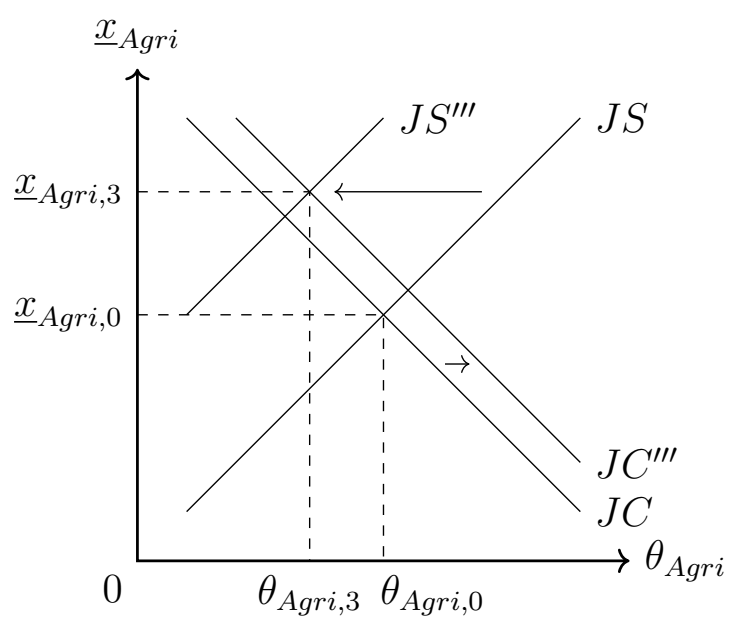

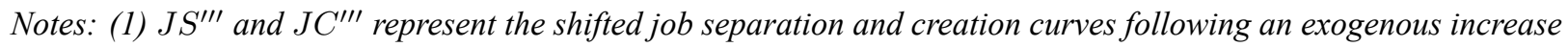
in the matching efficiency in the agricultural industry; (2) the intersection between the J $S^{\prime \prime \prime}$ and $J C^{\prime \prime \prime}$ curves represents the new (partial) equilibrium in the agricultural labor market, featuring $\left(\underline{x}_{A g r i, 3}, \theta_{\text {Agri,3 }}\right)$.

Now we turn to the 'pull' factors and analyze how they influence the job separation and finding rates in agriculture. We start with an exogenous decrease in the flow outside value for agricultural workers. Holding all else constant, this implies a rightward shift of the $J S$ curve to $J S^{*}$ as depicted in Figure 8. As a result, at the new equilibrium where $J S^{*}$ and $J C$ curves intersect, the reservation productivity declines whilst the agricultural labor market tightness rises; compared to the original equilibrium, the job separation rate falls whilst the job finding rate increases in the agricultural industry. The intuition is simple: the decrease in the agricultural worker's outside value enlarges the surplus to be shared, which then leads to lower realizations of idiosyncratic productivities - which were previously rejected - are now accepted; in other words, workers become less 'picky' and are less likely to separate. In practice, the decrease in the flow outside value for agricultural workers is often associated with a lack of education or skill depreciation, 
since they cannot satisfy the skill requirements for non-agricultural jobs and thus get stuck in agriculture.

Figure 8: The influence of lower flow outside value for agricultural workers on job separation and finding

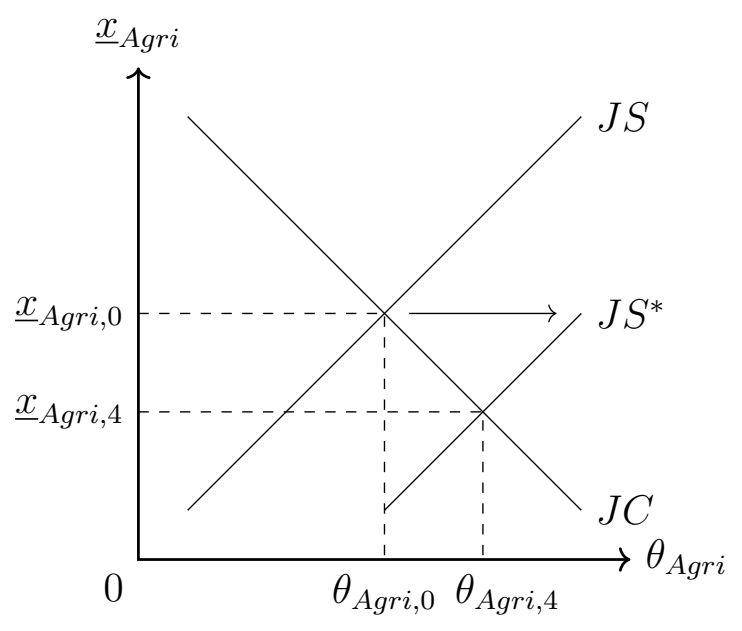

Notes: (1) J $S^{*}$ represents the shifted job separation curve following an exogenous decrease in the flow outside value faced by agricultural workers; (2) the intersection between the J $S^{*}$ and JC curves represents the new (partial) equilibrium in the agricultural labor market, featuring $\left(\underline{x}_{\text {Agri }, 4}, \theta_{\text {Agri }, 4}\right)$.

Another 'pull' factor to note is the deteriorating bargaining power of agricultural workers in their wages negotiation, which may also arise in the case of obsolete skills or agricultural clusters. Yet, the mechanism through which it hinders agricultural exodus differs from that illustrated in Figure 8; it instead involves rightward shifts of both the $J S$ and $J C$ curves. The dynamics are shown in Figure 9, and the new equilibrium is where the $J S^{* *}$ and $J C^{* *}$ curves intersect, provided that the shift in the $J C$ curve is relatively small. The new equilibrium features lower job separation but higher job finding probabilities in the agricultural industry because on the one hand, the lower bargaining power of workers shrinks their share of the matching surplus and discourages job separation, while on the other hand, the resulting greater bargaining power of firms increases their share of the matching surplus and promotes job creation. Hence, given the model predictions, it is expected that inadequate education and significant agricultural clusters would serve to dampen agricultural employment outflows.

Having illustrated how the 'push' and 'pull' factors in general determine the evolution of $E N$ (job separation) and NE (job finding) rates, we start to introduce some specific 'push' and 'pull' factors that will be taken into account in the empirical baseline. The selection is based on both empirical relevance and data availability. 
Figure 9: The influence of weaker bargaining of agricultural workers on job separation and finding

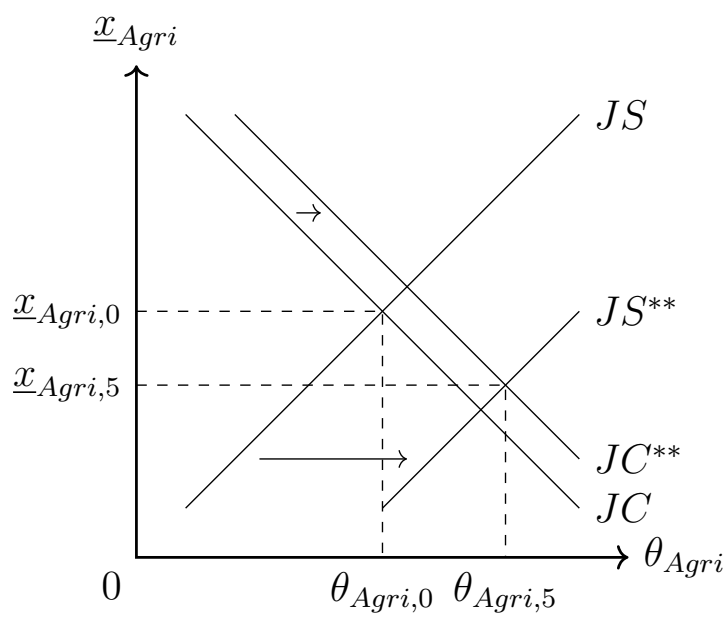

Notes: (1) $J S^{* *}$ and $J C^{* *}$ represent the shifted job separation and creation curves following an exogenous decrease in the bargaining power of agricultural workers; (2) the intersection between the $J S^{* *}$ and $J C^{* *}$ curves represents the new (partial) equilibrium in the agricultural labor market, featuring $\left(\underline{x}_{A g r i, 5}, \theta_{\text {Agri }, 5}\right)$.

\section{Empirically Available 'Push' Factors}

Real Wage Differentials. Having sustained average annual growth of $6.4 \%$ between 2010-2019, from an average of 4.6\% between 2001-2009, the Philippines' economy is considered one of the most dynamic economies in East Asia and the Pacific. However, the extent to which this growth has benefited agricultural workers, who represent a sizable share of the country's workforce (from $35 \%$ in 2005 to $24 \%$ in 2019), remains unclear. With a basic pay less than half that of a typical Filipino worker, agricultural workers represented roughly two of every three working poor in the country in 2012 (Briones, 2017a).

More strikingly, agricultural productivity in the Philippines is already lagging behind the average. As illustrated in Figure 1a, the agricultural TFP growth for the Philippines continued to decline during 2001-2016, even diving into a negative trajectory from 2013 onward. Compared to other ASEAN countries, the growth momentum in the Philippines' agricultural sector remains lackluster and far below the region's average. Such sustained low productivity - resulting from historical structural inefficiencies - is translated into large wage differentials (see Figure 10) between the agricultural and non-agricultural sectors, and these differences (which could be more severe by province) would induce workers to switch out of agriculture.

Labor Market Efficiency. In the absence of direct measures on labor market efficiency, we draw on the information from World Economic Forum Global Competitiveness Index (Schwab, 2019) in order to gauge how efficiently the Philippines' labor market has evolved. The Global 
Figure 10: Real wage differentials

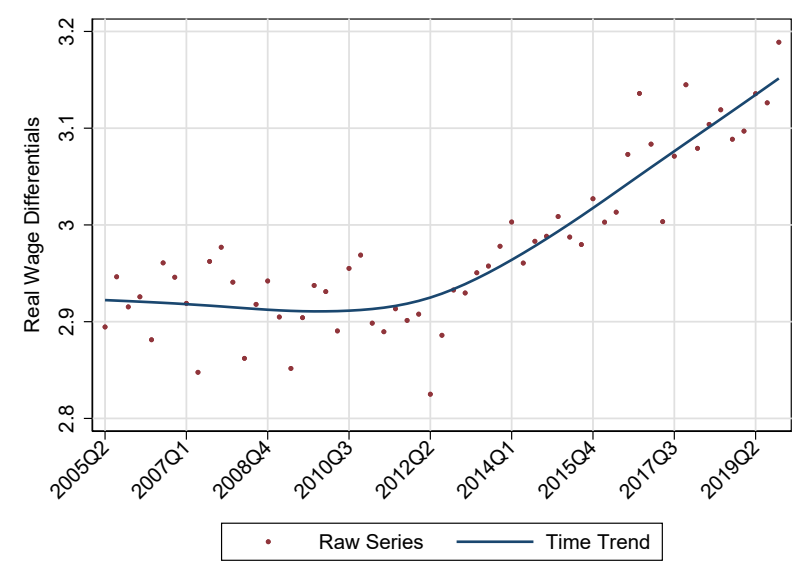

Source: Labor Force Survey, Philippine Statistics Authority. Real wage differentials are calculated as the natural logarithm of the differences in weighted average real hourly wages between non-agricultural and agricultural workers in each region, i.e., $w_{x, \text { Nonagri }}-w_{x, \text { Agri }}$ for region $x$. The weight applied to each individual is his/her share in the total employment in the agricultural/non-agricultural sector during the survey quarter, which is defined as the sum of the products of each agricultural/non-agricultural worker's weekly working hours and his/her final person weight in the survey quarter. The time series trend is estimated using the Hodrick-Prescott Filter with smoothing parameter of 1600.

Competitiveness Index builds on the Executive Opinion Survey. For the last 40 years, it has been a key ingredient of the index, and captured the views of surveyed business executives in member countries. Most questions in the survey ask respondents to evaluate on a scale of 1 (considered among the worst in the world) to 7 (considered among the best in the world) the performance on various topics of the country where the respondent operates. The sample frame reflects the underlying structure of the economy as it is (1) in proportion to the share of GDP by sector, (2) ensures the representation of both large- (more than 250 employees) and small-sized companies (250 employees or fewer), and (3) ensures that the chosen companies also have a sufficiently wide geographic coverage. For our purpose, we calculate the arithmetic average of the following five indices to construct the labor market efficiency index: flexibility of hiring and firing practices, cooperation in labor-employer relations, flexibility of wage determination, reliance on professional management, and the extent to which pay reflects the employee's productivity. ${ }^{7}$ In addition to data availability, we choose these indices following the literature that flexible contractual arrangement (e.g., International Monetary Fund (1999), Organisation for Economic Co-operation and Development (1994)) and efficient use of talents (e.g., Ostoj (2015)) are critical for the efficient functioning of labor market.

\footnotetext{
${ }^{7}$ As the sample frame aims to replicate an economy's sectoral composition and includes companies of different sizes, the country-level score of each question is the arithmetic mean of all answers in each country. That is, for a given question, all individual answers carry the same weight.
} 
As captured in Figure 11, despite some fluctuations, the index is on an increasing trend during the sample period. This implies improving employment absorption in the non-agricultural sector, which in theory reduces labor market frictions and strengthens the worker's ability to switch industries. As a result, the increasing labor market efficiency accompanies rising wage differentials and leads to significant employment outflows from agriculture to non-agriculture.

Figure 11: Labor market efficiency index

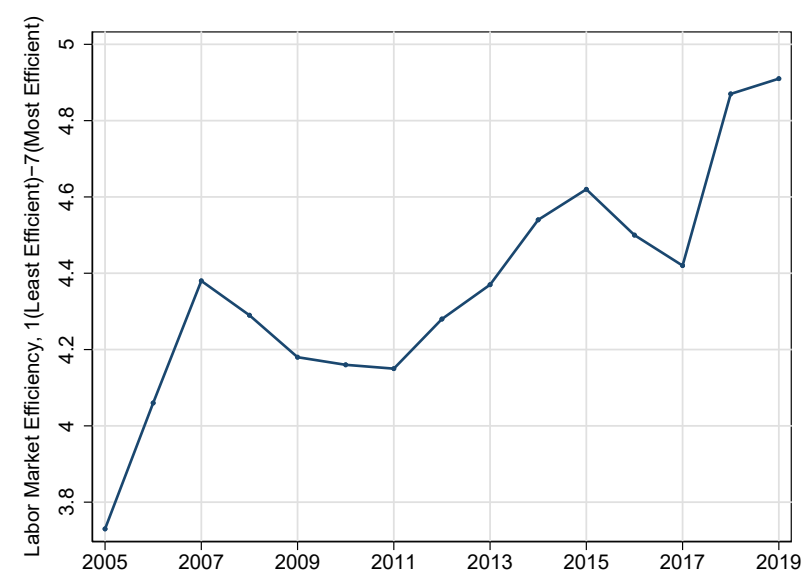

Source: Global Competitiveness Index, World Economic Forum.

Road Density. Similar to the role of labor market efficiency, we propose that the enhancement in road infrastructure, as measured by increasing road density, leads to lower reallocation costs and facilitates transitions out of the agricultural sector. Applying the information in 2018 and 2019 ATLAS published by the Department of Public Works and Highways (DPWH), we show in Figure 12 that national road density continued to intensify during the last ten years, despite the rapid pace of land developments in the Philippines. This can lead to better connectivity in agriculture and rural development, as it has been suggested that agricultural workers and those living in sparsely populated areas are effectively handicapped in mobility terms to access services, carry out everyday activities or maintain social links (European Commission, 2017).

Notwithstanding the overall increase, there is still wide disparity in road density across regions. In 2019, National Capital Region (NCR) has 188.24 kilometers of roads per square kilometer of land area whereas Western Visayas, the region with the second highest road density, has only 23.91 kilometer per square kilometer. Cagayan Valley has the lowest road density among all, at 6.73 kilometers per square kilometer. 
Figure 12: National road density

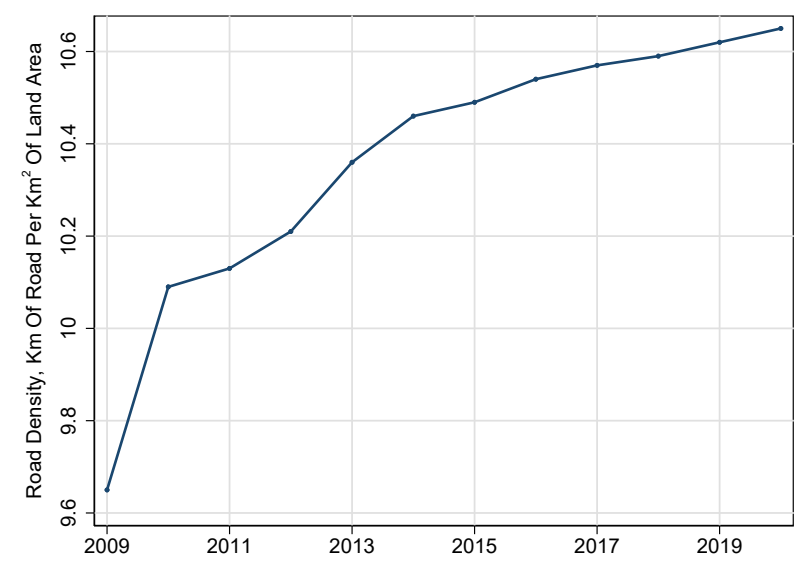

Source: 2018 \& 2019 ATLAS, Department of Public Works and Highways. Road density pertains to the ratio of the length of the country's total road network to the country's land area. The road network includes all roads in the country: motorways, highways, main or national roads, secondary or regional roads, and other urban and rural roads.

\section{Empirically Available 'Pull' Factors}

High School and College Education. The importance of education to labor reallocations is stressed in the literature that integrate migration and human capital theory, of which Sjaastad (1962) provided one of the first examples. This strand of literature (e.g., Maucorps et al. (2019), Tocco et al. (2013), and Bojnec and Dries (2005)) predicts that better-educated individuals or those with specific social capital (e.g., networks and contacts beneficial for intersectoral reallocations) can have a strong advantage over others because better access to information and low transaction costs are critical, especially when changing jobs also requires switching sectors. Furthermore, studies have found that inadequate human capital is a critical constraint, not only for agricultural labor restructuring, but also more generally for business development and economic activities in rural areas (Rizov and Swinnen, 2004).

As such, we gather information on both high school and college education attainment in the Philippines as a proxy for human capital development. We show in Figure 13 that, there is a significant difference in higher education attainment between agricultural and non-agricultural workers in the Philippines, with an average of over $80 \%$ of employed workers in non-agriculture but less than $50 \%$ in agriculture reaching at least high school education. This lower level of education constrains agricultural workers from seeking employment in more skill-demanding industries, and raises the costs they will potentially incur in switching from the agricultural to nonagricultural sectors (e.g., job-specific training). 
Figure 13: Share of employed workers with at least high school education

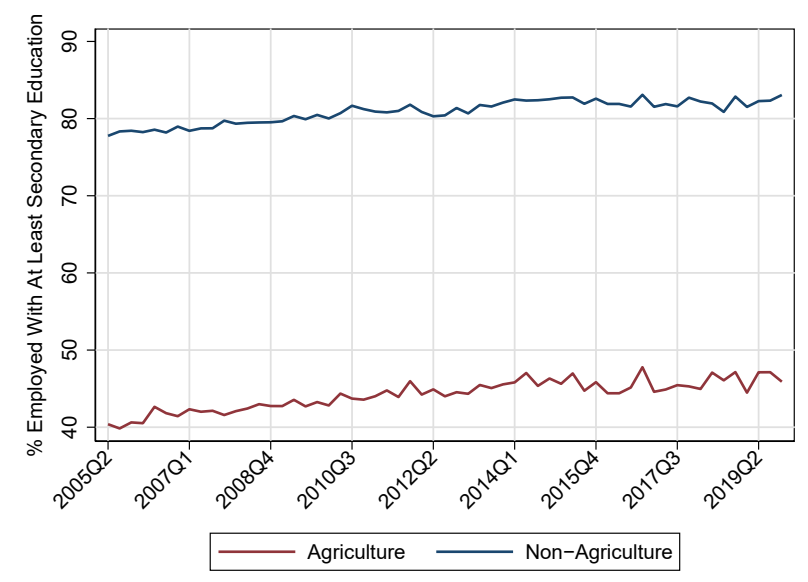

Source: Labor Force Survey, Philippine Statistics Authority.

Palay and Corn Production. We also examine the effects of industrial clusters on employment outflows from agriculture. Brenner and Gildner (2006) find that industrial concentration may have a negative impact on the local economic situation and resource allocation due to the lockins. For instance, if agriculture develops very well in a region, it might hinder other industries from also flowering there. This argument can be firstly based on the consideration that a successful industry with many employees increases prices for factors of production (e.g., labor) in the region. This makes the region less attractive for other industries as they are unable to benefit from economies of location in connection with the already existing industry.

Besides this simple cost argument, poverty (Carvalho et al., 2010), which is more prominent in rural areas that live off agriculture, creates psychological poverty traps, whereby people are too much focused on meeting immediate basic needs (feeding and sheltering) and forego investment opportunities due to impaired vision of the future and exorbitant time discount rates. Consequently, local agricultural clusters provide a disadvantageous ground for development in other industries and employment therein.

To measure the prevalence of agricultural clusters in an administrative region, ideally we would apply the agricultural/non-agricultural job vacancy data or the agricultural share of real valueadded in each region. However, neither of them is available for the entire sample period. Instead, we apply each region's share of total palay and corn production in the Philippines (see Figure 14) ${ }^{8}$ We hypothesize that, the higher the region's share is in the total palay and corn production,

\footnotetext{
${ }^{8}$ For reference, the regional share of total palay and corn production has a correlation of 0.46 with the agricultural share of real value-added in each region for 2009-2018, indicating that it is a reasonable proxy for agricultural clusters.
} 
the more dominant the agricultural sector is in the regional economy, and hence the larger the lock-in effect will be in restraining employment outflows from agriculture to non-agriculture.

Figure 14: Regional share of total palay and corn production

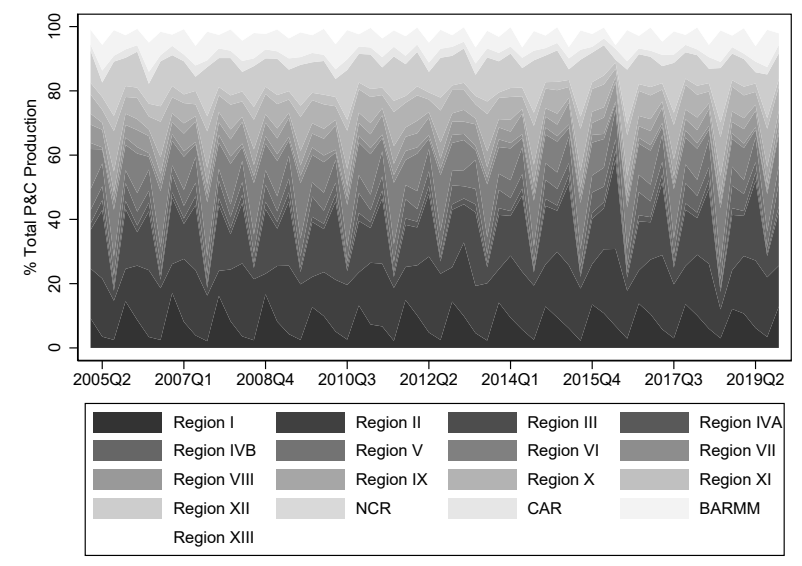

Source: Agriculture, Forestry, Fisheries Database, Philippine Statistics Authority. The regional shares of total palay and corn production are calculated from regional volume of production of palay and corn, of which the data source is Palay and Corn Production Survey (PCPS).

\section{EMPIRICAL ANALYSIS}

Having introduced some key aspects of the labor market in the Philippines, we present in this section the baseline regression results after a brief description of the Linear Probability Model that is applied in the estimation.

\section{A. Linear Probability Model}

In the previous sections, we propose a non-exhaustive but empirically available list of 'push' and 'pull' factors to account for the observed variations in the labor market transition rates. In order to identify the roles of these factors, we build a Linear Probability Model (LPM) of job separation and finding. The LPM allows us to easily and systematically control for changes in demographic and regional compositions over the sample period. Furthermore, despite the shortcoming as it does not constrain predicted probabilities to the unit interval, the LPM provides a reasonable direct estimate of the sample-average marginal effect on the probability that $y=1$ as $x$ changes, in addition to that it provides a good guide to which variables are statistically significant (Cameron and Trivedi, 2005).

Our LPM assumes that, for the binary outcome (Bernoulli trial), $E N$, and its associated vector of 
explanatory variables, $X$,

$$
\operatorname{Pr}(E N=1 \mid X=x)=x^{\prime} \beta,
$$

where $X$ includes real wage differentials, labor market efficiency index, logged road density, high school education dummy, college education dummy, each region's share of total palay and corn production (all of which are interacted with region dummies), worker's demographic characteristics (gender, age, and martial status), and year and quarter dummies. Throughout our estimations, we apply heteroskedasticity-robust standard errors. ${ }^{9}$ The same specification is also applied to the $N E$ rates and identifications therein.

Note that since the 2018 and 2019 DPWH ATLAS record road density data in 2009-2019 for all administrative regions except for Bangsamoro Autonomous Region in Muslim Mindanao (BARMM), in order to keep observations that would otherwise be dropped in the regressions, we apply the dummy variable adjustment as in Cohen et al. (2013) such that (1) BARMM is assigned the national average road density, and the road density for each region during 2005-2008 is assumed to equal their 2009 level; and (2) a dummy variable coded 1 if road density is imputed and 0 otherwise is included in the regressions.

\section{B. Baseline Regression Results}

Table 1 summarizes the average marginal effects (AMEs) of each of the aforementioned factors on the labor market transition rates. By examining the R-squared and $\mathrm{F}$ statistics associated with the joint significance of the identified 'push' and 'pull' factors, their interactions with region dummies, and demographic dummies, we find that even though the observed developments in the $E N$ and $N E$ rates are not so well replicated by the model, the proposed factors are jointly significant at the $1 \%$ level of significance, indicating their statistically significant explanatory power. ${ }^{10}$

The estimated AMEs of real wage differentials are significantly positive for the outcomes $E N_{A g r i}$

${ }^{9}$ Recall that the variance of a Bernoulli random variable $Y$ is given by $\operatorname{Var}(Y)=\operatorname{Pr}(Y=1) \times(1-\operatorname{Pr}(Y=$ $1)$ ). Hence, in a LPM with general form $Y_{i}=\beta_{0}+\beta_{1} X_{1, i}+\cdots+\beta_{k} X_{k, i}+u_{i}$, we can write the conditional variance of the error term as:

$$
\begin{aligned}
\operatorname{Var}\left(u_{i} \mid X_{1, i}, \ldots, X_{k, i}\right) & =\operatorname{Var}\left(Y_{i}-\left(\beta_{0}+\beta_{1} X_{1, i}+\cdots+\beta_{k} X_{k, i}\right) \mid X_{1, i}, \ldots, X_{k, i}\right) \\
& =\operatorname{Var}\left(Y_{i} \mid X_{1, i}, \ldots, X_{k, i}\right) \\
& =\operatorname{Pr}\left(Y_{i}=1 \mid X_{1, i}, \ldots, X_{k, i}\right) \times \operatorname{Pr}\left(1-\operatorname{Pr}\left(Y_{i}=1 \mid X_{1, i}, \ldots, X_{k, i}\right)\right) \\
& \neq \sigma_{u}^{2} .
\end{aligned}
$$

Hence, it is essential to use heteroskedasticity-robust standard errors in a LPM.

${ }^{10}$ For reference, the R-squared coefficients for the model in which we only regress each of the transition rates on region and time dummies are 0.0063 for $E N_{\text {Agri }}, 0.0027$ for $E N_{N o n a g r i}, 0.0146$ for $N E_{\text {Agri }}$, and 0.0260 for $N E_{\text {Nonagri }}$ respectively. 
Table 1: AMEs in the baseline LPM

\begin{tabular}{|c|c|c|c|c|}
\hline & $E N_{A g r i}$ & $E N_{\text {Nonagri }}$ & $N E_{\text {Agri }}$ & $N E_{\text {Nonagri }}$ \\
\hline \multicolumn{5}{|l|}{ 'Push' Factors } \\
\hline Real Wage Differentials & $\begin{array}{c}0.00947^{* * *} \\
(0.00245)\end{array}$ & $\begin{array}{c}-0.00572^{* * *} \\
(0.00203)\end{array}$ & $\begin{array}{c}-0.00683^{* * *} \\
(0.000991)\end{array}$ & $\begin{array}{c}0.00631^{* * *} \\
(0.00191)\end{array}$ \\
\hline Labor Market Efficiency & $\begin{array}{l}0.00675^{* *} \\
(0.00279)\end{array}$ & $\begin{array}{c}-0.0175^{* * *} \\
(0.00289)\end{array}$ & $\begin{array}{c}-0.00174 \\
(0.00167)\end{array}$ & $\begin{array}{l}0.0496^{* * *} \\
(0.00191)\end{array}$ \\
\hline Road Density & $\begin{array}{l}0.0487^{* *} \\
(0.0213)\end{array}$ & $\begin{array}{l}-0.0170 \\
(0.0192)\end{array}$ & $\begin{array}{c}-0.0768^{* * *} \\
(0.0115)\end{array}$ & $\begin{array}{c}0.0552^{* * *} \\
(0.0180)\end{array}$ \\
\hline \multicolumn{5}{|l|}{ 'Pull' Factors } \\
\hline High School Education & $\begin{array}{c}0.0204^{* * *} \\
(0.000473)\end{array}$ & $\begin{array}{l}0.00276^{* * *} \\
(0.000469)\end{array}$ & $\begin{array}{l}-0.0190^{* * *} \\
(0.000342)\end{array}$ & $\begin{array}{c}-0.00237^{* * *} \\
(0.000475)\end{array}$ \\
\hline College Education & $\begin{array}{c}0.0319^{* * *} \\
(0.000935)\end{array}$ & $\begin{array}{l}-0.0118^{* * *} \\
(0.000482)\end{array}$ & $\begin{array}{l}-0.0267^{* * *} \\
(0.000333)\end{array}$ & $\begin{array}{c}0.00173^{* * *} \\
(0.000510)\end{array}$ \\
\hline Palay \& Corn Production & $\begin{array}{c}-0.112^{* * *} \\
(0.0164)\end{array}$ & $\begin{array}{l}-0.0208 \\
(0.0170)\end{array}$ & $\begin{array}{c}0.00976 \\
(0.00807)\end{array}$ & $\begin{array}{c}-0.0340^{* *} \\
(0.0154)\end{array}$ \\
\hline \multicolumn{5}{|l|}{ Demographic Characteristics } \\
\hline Female & $\begin{array}{c}0.0925^{* * *} \\
(0.000627)\end{array}$ & $\begin{array}{c}0.0115^{* * *} \\
(0.000343)\end{array}$ & $\begin{array}{l}-0.0311^{* * *} \\
(0.000276)\end{array}$ & $\begin{array}{c}-0.0424^{* * *} \\
(0.000445)\end{array}$ \\
\hline Age $25-34$ & $\begin{array}{l}-0.0541^{* * *} \\
(0.000838)\end{array}$ & $\begin{array}{l}-0.0388^{* * *} \\
(0.000616)\end{array}$ & $\begin{array}{l}0.00568^{* * *} \\
(0.000297)\end{array}$ & $\begin{array}{c}0.0300^{* * *} \\
(0.000586)\end{array}$ \\
\hline Age $35-44$ & $\begin{array}{l}-0.0628^{* * *} \\
(0.000864)\end{array}$ & $\begin{array}{l}-0.0529^{* * *} \\
(0.000643)\end{array}$ & $\begin{array}{l}0.00889^{* * *} \\
(0.000369)\end{array}$ & $\begin{array}{c}0.0327^{* * *} \\
(0.000697)\end{array}$ \\
\hline Age $45-54$ & $\begin{array}{c}-0.0627^{* * *} \\
(0.000890)\end{array}$ & $\begin{array}{l}-0.0533^{* * *} \\
(0.000672)\end{array}$ & $\begin{array}{l}0.00866^{* * *} \\
(0.000428)\end{array}$ & $\begin{array}{c}0.0232^{* * *} \\
(0.000729)\end{array}$ \\
\hline Age $55-64$ & $\begin{array}{c}-0.0534^{* * *} \\
(0.000956)\end{array}$ & $\begin{array}{l}-0.0487^{* * *} \\
(0.000775)\end{array}$ & $\begin{array}{c}-0.00201^{* * *} \\
(0.000436)\end{array}$ & $\begin{array}{c}-0.00668^{* * *} \\
(0.000691)\end{array}$ \\
\hline Married & $\begin{array}{l}-0.0202^{* * *} \\
(0.000652)\end{array}$ & $\begin{array}{l}-0.0132^{* * *} \\
(0.000473)\end{array}$ & $\begin{array}{l}0.00724^{* * *} \\
(0.000280)\end{array}$ & $\begin{array}{l}0.00757^{* * *} \\
(0.000553)\end{array}$ \\
\hline Widowed & $\begin{array}{c}-0.0361^{* * *} \\
(0.00134)\end{array}$ & $\begin{array}{l}-0.0124^{* * *} \\
(0.000969)\end{array}$ & $\begin{array}{l}0.00513^{* * *} \\
(0.000658)\end{array}$ & $\begin{array}{l}0.0141^{* * *} \\
(0.00112)\end{array}$ \\
\hline Divorce/Separate/Annulled & $\begin{array}{c}-0.0214^{* * *} \\
(0.00177)\end{array}$ & $\begin{array}{c}-0.00430^{* * *} \\
(0.00112)\end{array}$ & $\begin{array}{l}0.00703^{* * *} \\
(0.000889)\end{array}$ & $\begin{array}{l}0.0278^{* * *} \\
(0.00196)\end{array}$ \\
\hline Observations & 1437827 & 2553367 & 2448570 & 2496782 \\
\hline R-squared & 0.0536 & 0.0162 & 0.0383 & 0.0428 \\
\hline Joint Significance (F-stat) & 333.57 & 178.40 & 173.48 & 144.22 \\
\hline Region FE & Yes & Yes & Yes & Yes \\
\hline Year \& Quarter FE & Yes & Yes & Yes & Yes \\
\hline $\begin{array}{l}\text { Notes: } \\
\text { (1) All standard errors (in parent } \\
\text { (2) }{ }^{*} p<0.10,{ }^{* *} p<0.05,{ }^{* *} \\
\text { (3) Joint significance (F-stat) me }\end{array}$ & $\begin{array}{l}\text { es) are hete } \\
0.01\end{array}$ & sticity robus & ; & ig the \\
\hline
\end{tabular}

\section{CInternational Monetary Fund. Not for Redistribution}


and $N E_{\text {Nonagri }}$, whilst significantly negative for the outcomes $E N_{N o n a g r i}$ and $N E_{\text {Agri }}$. Specifically, for a $1 \%$ increase in real wage differentials, on average, the probability of flowing into non-employment from agriculture increases by approximately 0.01 percentage point, whereas the probability of flowing out of non-employment into agriculture decreases by 0.007 percentage point. This implies that widening real wage differentials give rise to non-negligible incentives for workers to switch out of agriculture and direct their search effort elsewhere. Moving on to labor market efficiency and road density, we find that both of them have a positive and highly significant effect on job separations out of agriculture and job findings into non-agriculture. This implies that the industry switching motive becomes especially prominent when labor market efficiency is improving in the non-agricultural sector and transport infrastructure is upgraded, as agricultural workers can switch industries more freely.

In terms of high school and college education, we find that both of them contribute to employment outflows from agriculture through higher $E N_{A g r i}$ and lower $N E_{\text {Agri }}$; however, in levels, college education plays a more significant role in driving the outflows than high school education. This confirms our proposition in Figure 13 that the lack of sufficient education, especially at higher levels, suppresses employment outflows from agriculture and essentially drags workers back to agricultural employment. Furthermore, if we compare the AMEs of college education on $E N_{N o n a g r i}$ and $N E_{\text {Nonagri }}$ to those of high school education, we find that it is only by undertaking college education that workers can find and hold on to their non-agricultural jobs more easily. ${ }^{11}$ Hence, given that only less than $10 \%$ of employed workers in agriculture reach college education, this further attenuates employment outflows from agriculture to non-agriculture.

As for the regional share of total palay and corn production, its negative and significant AMEs on $E N_{A g r i}$ and $N E_{N o n a g r i}$ unequivocally indicate the negative impacts of agricultural clusters, as the difficulty to switch out of the agricultural sector is heightened when the region's economy is more dominated by agriculture. However, the regional share of total palay and corn production does not seem to have a significant impact on the outflows of non-agricultural employment or inflows into agricultural employment.

Lastly, by examining the AMEs of demographic dummies, we find that the gender bias is present in the Philippines as females separate significantly more often and are less likely to find jobs in both agricultural and non-agricultural sectors. Furthermore, though not uniformly, workers become significantly less likely to separate when they age. The latter observation is likely to be associated with experience and learning about industrial fit as in, for instance, Gervais et al. (2016)

\footnotetext{
${ }^{11}$ This seems to be driven mostly by transition rates for high-skilled non-agricultural jobs. For low-skilled nonagricultural jobs, having college education, as in the case of agriculture, incentivizes workers to separate more and find less. Nonetheless, high school education seems to have a larger impact on both job separation and finding rates in agriculture than those in low-skilled non-agriculture. See the third robustness check in Section C for details.
} 
and Menzio et al. (2016). The intuition is that, in order to learn the industry in which they are most productive and earn the most wages, workers sample industries over their careers. Because young workers are more likely to be in matches that represent a poor industrial fit, they spend more time in transitioning between industries. As for old workers, since they have drawn more matches, they are more likely to be in ones with higher idiosyncratic productivity, and hence, less likely to separate. In this way, we expect a declining age profile of job separation.

\section{Robustness Checks}

In the previous section, we identify several 'push' and 'pull' factors in explaining the observed changes in the $E N$ and $N E$ rates. In what follows, we elaborate on the empirical results along several dimensions. We aim to apply the following exercises as robustness checks and to further illustrate the driving forces of the agricultural exodus in the Philippines.

\section{Cross-Region Wage Differentials and Industry Switching via Migration}

Geographic mobility is a potentially powerful way of escaping non-employment and improving one's income. The literature (e.g., Kennan and Walker (2011)) have indicated that migration decisions are influenced to a substantial extent by income prospects. The link between income and migration decisions is driven both by geographic differences in mean wages and by a tendency to move in search of a better locational match when the income realization in the current location is unfavorable. This finding leads us to speculate how much of the intersectoral labor reallocations in the Philippines are accompanied by geographic reallocations.

Figure 15: Within-region and cross-region real wage differentials

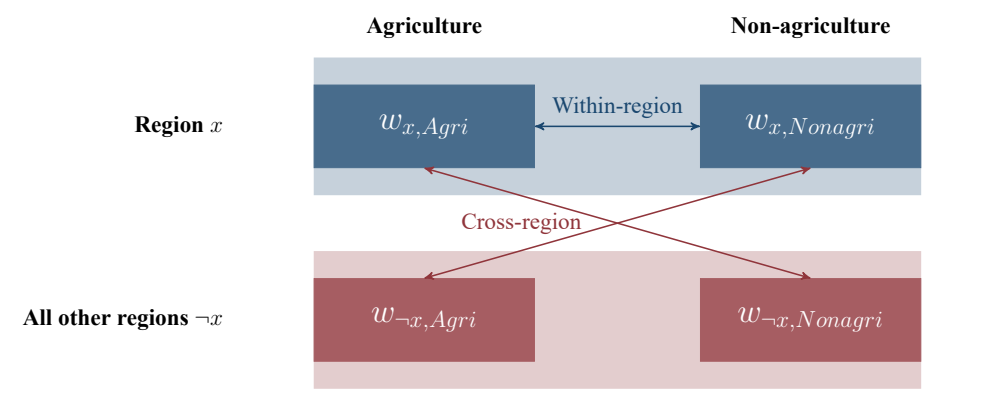

Although the LFS data do not allow us to track each individual beyond two periods and across regions, we estimate how much the effects of cross-region real wage differentials are on the labor market transition rates, and show indirectly that some job separations/findings are indeed triggered by them, as individuals migrate from one region to another in order to switch industries. Specifically, we calculate both the within-region and cross-region real wage differentials (see 
Figure 15 for an illustration). The within-region real wage differentials relate to the same measure as the one applied in the main regressions, which is the natural logarithm of the differences in weighted average real hourly wages between non-agricultural and agricultural workers in each region, i.e., $w_{x, \text { Nonagri }}-w_{x, \text { Agri }}$ for region $x$. In terms of cross-region real wage differentials, the definition varies depending on whether the dependent variable (i.e., $E N$ or $N E$ rate) is for agricultural or non-agricultural workers. More specifically, when we study the transition rates for agricultural workers, the cross-region real wage differentials in region $x$ can be calculated as the natural logarithm of the differences between weighted average real hourly wages earned by nonagricultural workers in all other regions and those earned by agricultural workers in region $x$, i.e., $w_{\neg x, \text { Nonagri }}-w_{x, \text { Agri }}$. For non-agricultural workers, it is computed as $w_{x, \text { Nonagri }}-w_{\neg x, \text { Agri }}$ for region $x .{ }^{12}$ In this way, we are able to capture the magnitude of geographic wage differentials, and study the responsiveness of intersectoral labor flows to them.

Table 2: AMEs in the LPM with cross-region real wage differentials

\begin{tabular}{|c|c|c|c|c|}
\hline & \multicolumn{2}{|c|}{ Agriculture } & \multicolumn{2}{|c|}{ Non-Agriculture } \\
\hline & $E N_{\text {Agri }}$ & $N E_{\text {Agri }}$ & $E N_{\text {Nonagri }}$ & $N E_{\text {Nonagri }}$ \\
\hline Within-Region Real Wage Differentials & $\begin{array}{l}0.0112^{* * *} \\
(0.00305)\end{array}$ & $\begin{array}{c}-0.0147^{* * *} \\
(0.00132)\end{array}$ & $\begin{array}{l}-0.00334 \\
(0.00247)\end{array}$ & $\begin{array}{l}0.0108^{* * *} \\
(0.00241)\end{array}$ \\
\hline Cross-Region Real Wage Differentials & $\begin{array}{c}0.0106^{*} \\
(0.00546)\end{array}$ & $\begin{array}{l}0.0328^{* * *} \\
(0.00222)\end{array}$ & $\begin{array}{c}-0.00945^{* * *} \\
(0.00362)\end{array}$ & $\begin{array}{l}0.0232^{* * *} \\
(0.00348)\end{array}$ \\
\hline Labor Market Efficiency & $\begin{array}{l}0.0122^{* * *} \\
(0.00293)\end{array}$ & $\begin{array}{c}0.00135 \\
(0.00172)\end{array}$ & $\begin{array}{c}-0.0121^{* * *} \\
(0.00298)\end{array}$ & $\begin{array}{l}0.0416^{* * *} \\
(0.00196)\end{array}$ \\
\hline Road Density & $\begin{array}{c}0.0198 \\
(0.0225)\end{array}$ & $\begin{array}{c}-0.0956^{* * *} \\
(0.0120)\end{array}$ & $\begin{array}{c}-0.0283 \\
(0.0203)\end{array}$ & $\begin{array}{c}0.0266 \\
(0.0186)\end{array}$ \\
\hline High School Education & $\begin{array}{c}0.0204^{* * *} \\
(0.000473)\end{array}$ & $\begin{array}{l}-0.0195^{* * *} \\
(0.000352)\end{array}$ & $\begin{array}{l}0.00275^{* * *} \\
(0.000469)\end{array}$ & $\begin{array}{c}-0.00238^{* * *} \\
(0.000476)\end{array}$ \\
\hline College Education & $\begin{array}{c}0.0320^{* * *} \\
(0.000935)\end{array}$ & $\begin{array}{l}-0.0275^{* * *} \\
(0.000342)\end{array}$ & $\begin{array}{l}-0.0118^{* * *} \\
(0.000482)\end{array}$ & $\begin{array}{l}0.00174^{* * *} \\
(0.000511)\end{array}$ \\
\hline Palay \& Corn Production & $\begin{array}{c}-0.104^{* * *} \\
(0.0172)\end{array}$ & $\begin{array}{c}0.00536 \\
(0.00903)\end{array}$ & $\begin{array}{l}-0.0222 \\
(0.0171)\end{array}$ & $\begin{array}{c}-0.0370^{* *} \\
(0.0155)\end{array}$ \\
\hline Observations & 1437160 & 2380033 & 2551595 & 2491172 \\
\hline $\begin{array}{l}\text { Notes: } \\
\text { (1) All standard errors (in parentheses) are hete } \\
\text { (2) }{ }^{*} p<0.10,{ }^{* *} p<0.05,{ }^{* * *} p<0.01 \text {; } \\
\text { (3) Demographic, region, and year \& quarter d } \\
\text { (4) The definitions of cross-region real wage di } \\
\text { workers; see the above text for details. }\end{array}$ & $\begin{array}{l}\text { kedasticity rob } \\
\text { mies are includ } \\
\text { rentials differ b }\end{array}$ & $\begin{array}{l}\text { ust; } \\
\text { ed; }\end{array}$ & . & al \\
\hline
\end{tabular}

Table 2 gives the estimation results. We see that after taking into account cross-region real wage differentials, the AMEs of the original 'push' and 'pull' factors, including within-region real wage differentials, are robust in general. As for cross-region real wage differentials, their marginal

\footnotetext{
${ }^{12}$ Such calculations make the AMEs comparable across transition rates in agriculture and non-agriculture, as any increase in the wage differentials implies a widening wage gap between non-agricultural and agricultural workers.
} 
effects are highly significant, and the signs imply that greater cross-region real wage differentials give rise to more job separations and findings in the agricultural sector, whilst fewer separations but more findings in the non-agricultural sectors. In particular, the positive effect of cross-region real wage differentials on $N E_{\text {Agri }}$ points to the likely circumstance that significant employment outflows from agriculture lessen the competition within, and thus result in higher job finding rate in agriculture. In addition, thin cross-regional non-agricultural labor markets, such that the actual cost of migration outweighs the potential benefit, can also reduce geographic mobility and essentially make agricultural workers move less (Balgova, 2020).

\section{EE Transitions}

Despite the rare occurrence of $E E$ transitions in the LFS, they still represent an integral part of labor market flows in theory (see Figure 2). As presented in Figure 16, by inspecting time series trends of the $E E$ rates, we find that in levels, the $E E$ rate from agriculture to non-agriculture is higher than the opposite; both trends are decreasing in the early sample before they diverge as the $E E$ rate from agriculture to non-agriculture rises significantly, while the $E E$ rate from nonagriculture to agriculture remains relatively stable.

Figure 16: Time series trends of the $E E$ rates

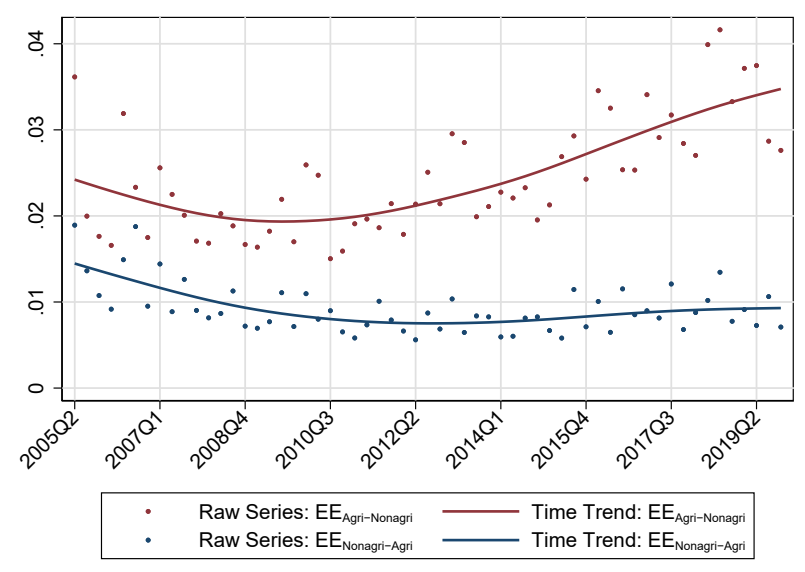

Source: Labor Force Survey, Philippine Statistics Authority. The trends are estimated using the Hodrick-Prescott Filter with smoothing parameter of 1600.

We then estimate how much the proposed 'push' and 'pull' factors explain the observed evolution in the $E E$ rates. The results are summarized in Table 3. We firstly find that only the AME of real wage differentials on $E E$ transitions from non-agriculture to agriculture is negative and statistically significant. This implies that as wage differentials widen, non-agricultural workers become more reluctant to separate, no matter whether it is separation into non-employment (as also captured by the negative and statistically significant AME of real wage differentials on 
$E N_{\text {Nonagri }}$ in Table 1), or separation to agricultural employment. In contrast, real wage differentials do not seem to affect the job-to-job transitions out of agriculture. Combined with that the marginal effects of labor market efficiency, high school, and college education are positive and statistically significant, this result highlights the importance of providing means to agricultural workers so as to enhance their ability to switch industries freely.

Table 3: AMEs in the LPM for $E E$ transitions

\begin{tabular}{lcc}
\hline \hline & $E E_{\text {Agri } \rightarrow \text { Nonagri }}$ & $E E_{\text {Nonagri } \rightarrow \text { Agri }}$ \\
\hline Real Wage Differentials & -0.00168 & $-0.00298^{* * *}$ \\
& $(0.00183)$ & $(0.000750)$ \\
Labor Market Efficiency & $0.0121^{* * *}$ & $-0.00872^{* * *}$ \\
& $(0.00164)$ & $(0.00184)$ \\
& -0.00211 & -0.0132 \\
Road Density & $(0.0142)$ & $(0.00845)$ \\
& & \\
High School Education & $0.00749^{* * *}$ & $-0.0103^{* * *}$ \\
& $(0.000340)$ & $(0.000238)$ \\
College Education & $0.00821^{* * *}$ & $-0.0157^{* * *}$ \\
& $(0.000629)$ & $(0.000225)$ \\
Palay \& Corn Production & $-0.0314^{* *}$ & $-0.0283^{* * *}$ \\
& $(0.0129)$ & $(0.00630)$ \\
\hline Observations & 1386682 & 2450249 \\
\hline \hline Notes: & & \\
(1) All standard errors (in parentheses) are heteroskedasticity robust; \\
(2) ${ }^{*} p<0.10, * *$ \\
(3) Demographic, region, and year \& quarter dummies are included.
\end{tabular}

We also find through the negative AMEs of the regional share of total palay and corn production that workers cling to their jobs, no matter whether they are agricultural or non-agricultural, when the regional economy is more dominated by agriculture. This is expected as on the one hand, agricultural workers face more difficulties to switch out of agriculture when the cluster effect takes hold; on the other hand, non-agricultural workers become more reluctant to separate due to the associated wages loss from job separation and limited re-employment opportunities back into non-agriculture.

\section{Switching From Agriculture to Other Low-Skilled Industries}

In this section, we study the transition rates in low-skilled non-agricultural industries instead of the non-agricultural sectors as a whole. This exercise adds to the discussion that the reallocations of agricultural workers into low-skilled non-agricultural industries may be more practically fea- 
sible. First of all, there might be large static productivity gains when labor reallocates from agriculture to non-agricultural industries. Sizable productivity and wage gaps between agriculture and non-agricultural industries have been measured in several studies and have been shown to be larger in developing economies (e.g., Gollin et al. (2014), Lagakos and Waugh (2013), Restuccia et al. (2008), and Caselli (2005)). To the extent that these gaps arise from the existence of inefficiencies and frictions in the economy, reallocations of labor from agriculture to non-agricultural industries are both productivity- and welfare-enhancing. ${ }^{13}$ Secondly, there can be dynamic productivity gains when labor reallocates towards non-agriculture if this industry is subject to agglomeration externalities and knowledge spillovers (e.g., Matsuyama (1992)). Lastly, inducing labor reallocations from agriculture towards low-skilled non-agricultural industries can be more practically sound than reallocations to high-skilled industries, as the skill requirements might be less demanding for such transitions to take place.

Figure 17: Average share of employed workers with at least high school education, by industry

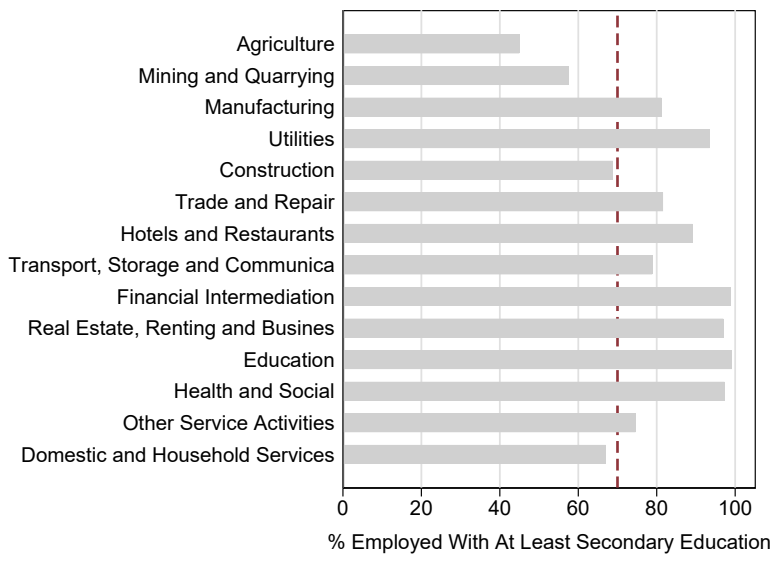

Source: Labor Force Survey, Philippine Statistics Authority.

We define low-skilled non-agricultural industries as those which have an average share of employed workers with at least high school education below $70 \%$, i.e., mining and quarrying, construction, and domestic and household services, as indicated in Figure 17. We then estimate the average marginal effects of the proposed 'push' and 'pull' factors on the transition rates in agriculture and low-skilled non-agricultural industries respectively. The results are summarized in Table 4. We find that changes in labor market efficiency are driving the employment outflows from agriculture towards those low-skilled industries, whilst real wage differentials and road density only play a minor role. As for high school and college education, they accelerate employ-

\footnotetext{
${ }^{13}$ Although this view has been recently challenged by Bustos et al. (2020) that low-skilled workers leaving agriculture reinforces comparative advantage in the least skill-intensive manufacturing industries, which reduces the incentives to innovate and slows down growth.
} 
Table 4: AMEs in the LPM for transitions from agriculture to other low-skilled industries

\begin{tabular}{lcccc}
\hline \hline & $E N_{\text {Agri }}$ & $E N_{\text {Lowskilled }}$ & $N E_{\text {Agri }}$ & $N E_{\text {Lowskilled }}$ \\
\hline Real Wage Differentials & -0.00231 & -0.00515 & $-0.00334^{* * *}$ & $-0.00272^{* * *}$ \\
& $(0.00196)$ & $(0.00473)$ & $(0.000750)$ & $(0.000611)$ \\
Labor Market Efficiency & $0.0115^{* * *}$ & $-0.0351^{* *}$ & -0.00193 & $0.0104^{* * *}$ \\
& $(0.00302)$ & $(0.0165)$ & $(0.00161)$ & $(0.000887)$ \\
& & & & \\
Road Density & -0.00373 & $0.146^{* *}$ & $-0.0240^{* *}$ & 0.00528 \\
& $(0.0222)$ & $(0.0567)$ & $(0.0106)$ & $(0.00788)$ \\
High School Education & $0.0204^{* * *}$ & $0.00357^{* * *}$ & $-0.0191^{* * *}$ & $-0.00534^{* * *}$ \\
& $(0.000473)$ & $(0.00113)$ & $(0.000345)$ & $(0.000277)$ \\
College Education & $0.0320^{* * *}$ & $0.00621^{* * *}$ & $-0.0269^{* * *}$ & $-0.0100^{* * *}$ \\
& $(0.000935)$ & $(0.00167)$ & $(0.000335)$ & $(0.000269)$ \\
Palay \& Corn Production & $-0.106^{* * *}$ & $-0.123^{* *}$ & $0.0190^{* *}$ & 0.00159 \\
& $(0.0162)$ & $(0.0484)$ & $(0.00809)$ & $(0.00727)$ \\
\hline Observations & 1437666 & 394678 & 2430806 & 2407870 \\
\hline \hline $\begin{array}{l}\text { Notes: } \\
\text { (1) All standard errors (in parentheses) are heteroskedasticity robust; }\end{array}$ \\
$\begin{array}{l}\text { (2) }{ }^{*} p<0.10,{ }^{* *} p<0.05,{ }^{* * *} p<0.01 ; \\
\text { (3) Demographic, region, and year \& quarter dummies are included. }\end{array}$ & \\
& & & \\
\end{tabular}

ment outflows from the agricultural sector mainly through increasing the separation margin and shrinking the job finding probability in agriculture. Here, an interesting observation is that while the job separation rate in low-skilled non-agricultural industries increases with high school and college education, the job finding rate in these industries also decreases with them. The latter differs from the job finding rate in non-agriculture as a whole (see Table 1), reflecting the role of college education in high-skilled industries. As for its cause, we argue that it is directly related to the strong incentive for skilled labor to switch away from low-skilled industries in general. Nonetheless, there are large differences in the size of AMEs of high school and college education on labor market transition rates between agricultural and low-skilled non-agricultural sectors.

\section{Other Robustness Checks}

We also perform three other robustness checks with different regression specifications. Firstly, we explore the extent to which our baseline regression results are affected during specific time periods. We apply two exercises in Appendix II, in which we add a time dummy indicating 2005Q22008Q1 and 2017Q1-2019Q4 respectively in the LPM of each labor market transition rate, and interact the time dummy with the proposed 'push' and 'pull' factors. We find that the results are robust in general, with no significant differences in the coefficients of 'push' and 'pull' factors over time. Secondly, we report in Table III.1 the estimation results corresponding to a specifi- 
cation with clustered standard errors at the regional level. We find that even though real wage differentials and road density do not significantly explain the variations in the $E N$ and $N E$ rates for either agricultural or non-agricultural workers anymore, the remaining 'push' and 'pull' factors still have their explanatory power, especially for high school and college education. Lastly, we re-estimate the AMEs of each of the proposed 'push' and 'pull' factors using a logit model. The results are largely similar to what we observe in the LPM, and are presented in Table III.2.

\section{WHICH DRIVERS HAVE THE LARGEST IMPACT?}

As explained in the previous section, each of the proposed 'push' and 'pull' factors is statistically significant in explaining the observed variations in the labor market transition rates. However, which of them are more economically significant in driving the employment outflows from agriculture to non-agriculture? To answer this question, we calculate the economic significance of each factor as to how much the $E N$ or $N E$ rate will change per standard deviation increase in the identified factor. For high school and college education, since they are dummy variables, we measure their economic significance by the corresponding AMEs that are presented in Table 1. The results are shown in Figure 18. From the panels, we see that real wage differentials are highly statistically significant but the impacts are very limited. ${ }^{14}$ On the contrary, high school and college education are more important, especially for job separation from agriculture. Similarly, road density plays a more economically significant role, especially for job finding in both agriculture and non-agriculture.

The above exercise emphasizes the importance of promoting post-primary education in order to facilitate intersectoral labor reallocations. For agricultural workers, returns to off-farm labor are constrained by their low levels of education and by the large disparities in higher education attainment between agricultural and non-agricultural workers (recall Figure 13). Since the main dividing line between high- and low-paying jobs is skills, more educated workers are more likely to have access to rewarding non-agricultural jobs. In addition, considering the regional differences in higher education attainment, from Figures 19, we see that the effect of high school education in driving employment outflows from agriculture is general across regions, but often even larger for regions with less education through higher $E N_{\text {Agri }}$ and lower $N E_{\text {Agri }}$. This implies that public investment in education can lean towards those underdeveloped regions with low access to high school education. In addition, we find in Figure 20 that promoting high school education, especially among the young, leads to more significant labor reallocations through higher job sep-

\footnotetext{
${ }^{14} \mathrm{We}$ also calculate the economic significance of cross-region real wage differentials, and show that it is similar to that of within-region real wage differentials.
} 
Figure 18: Economic significance
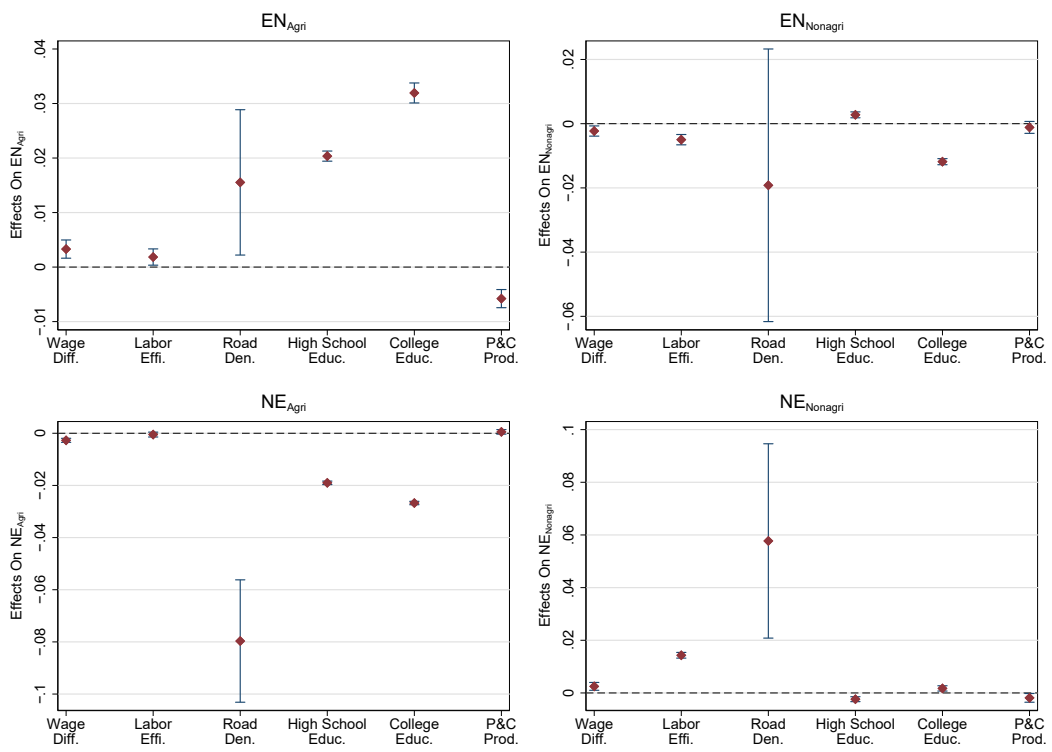

Source: Labor Force Survey, Philippine Statistics Authority.

aration and lower job finding in agriculture. ${ }^{15}$ Furthermore, females benefit proportionally more from higher education as they experience both significantly higher job separation in agriculture and job finding in non-agriculture than males when undertaking high school education (see Figure 21). Lastly, we take a step forward by examining the effects of college education on intersectoral labor reallocations. By comparing the AMEs of college education on labor market transition rates across regions, age, and gender in Figures III.1, III.2, and III.3 respectively, we find similar results to those associated with only high school education in terms of transitions in and out of agriculture; yet, as for transitions in and out of non-agriculture, it is worth noting that college education seems more effective for workers (especially the females) to find and keep their nonagricultural jobs.

In addition to higher education, improving transport infrastructure also turns out to be a practical and economically significant option of facilitating labor reallocations from agriculture. We show in Figure 22 that, though not uniformly, in regions with low levels of road density, the marginal increase in road density induces larger outflows from agriculture to non-agriculture (higher $E N_{\text {Agri }}$ and $N E_{\text {Nonagri }}$, in general). This result is consistent with the broad literature arguing that transport infrastructure promotes intersectoral reallocations, and thus increases welfare, especially in rural and underdeveloped areas (e.g., Donaldson (2018) and Yang (2018)). It is also in line with the growing interest among policymakers worldwide in using infrastructure

\footnotetext{
${ }^{15}$ However, the effect could be limited as the problem of aging population in agriculture takes hold (i.e., workers with age from 35 to 64 represent a significant proportion of labor employed in the agricultural sector).
} 
investments both as a short-term fiscal policy instrument, and more importantly, as a long-term growth generator, which essentially calls for better resource reallocations between industries with significant productivity differences.

Figure 19: AMEs of high school education, by region
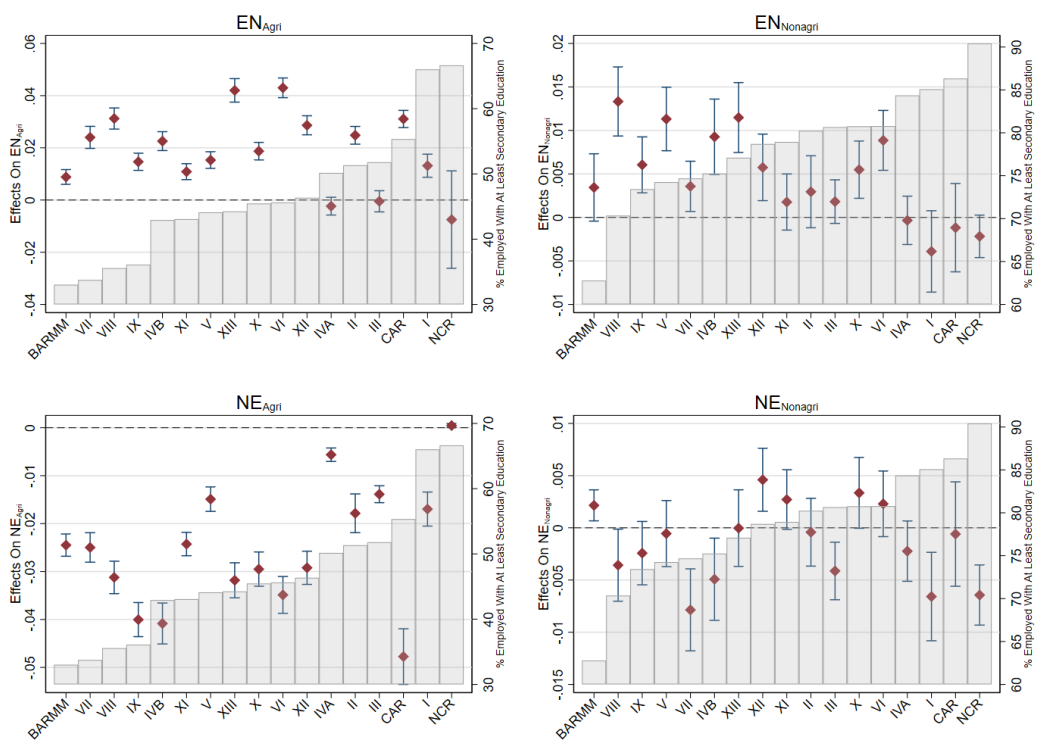

Source: Labor Force Survey, Philippine Statistics Authority.

Figure 20: AMEs of high school education, by age
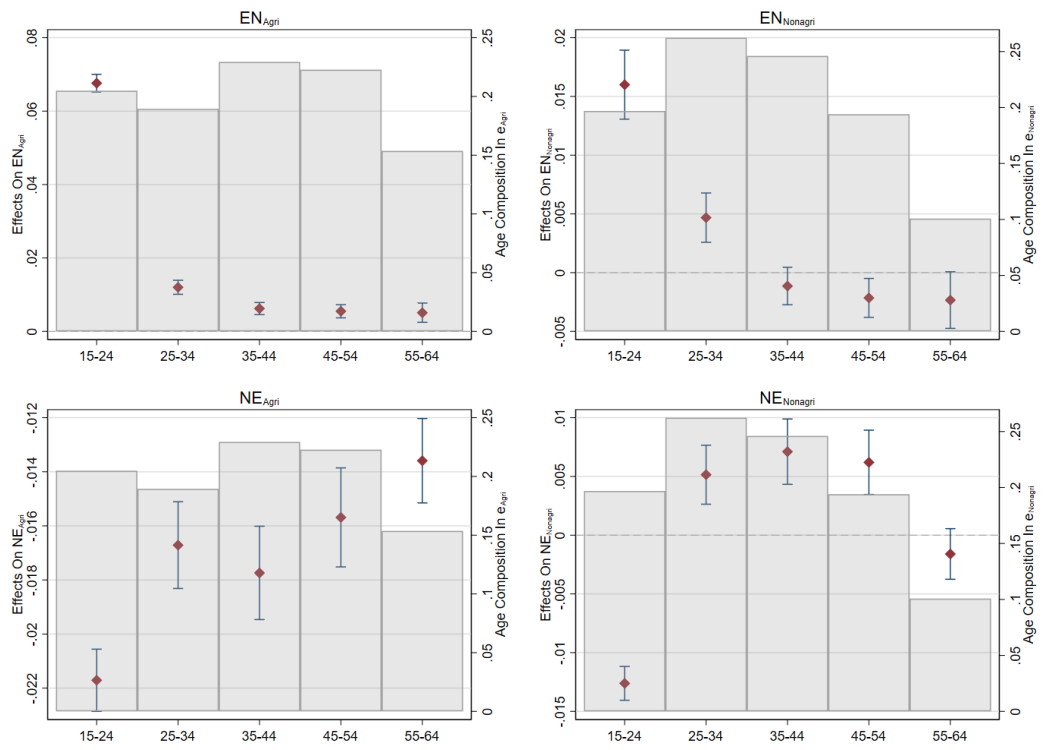

Source: Labor Force Survey, Philippine Statistics Authority. The underlying LPM includes interaction terms between high school education dummy, region dummies, and age dummies. 
Figure 21: AMEs of high school education, by gender
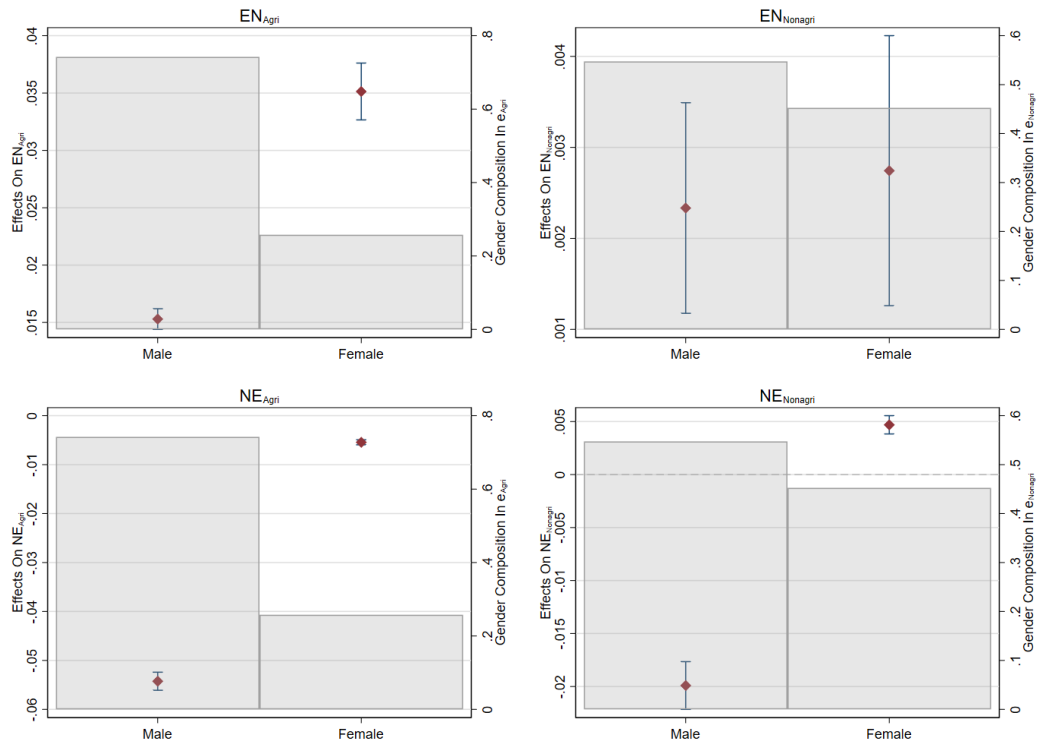

Source: Labor Force Survey, Philippine Statistics Authority. The underlying LPM includes interaction terms between high school education dummy, region dummies, and gender dummies.

Figure 22: AMEs of road density, by region
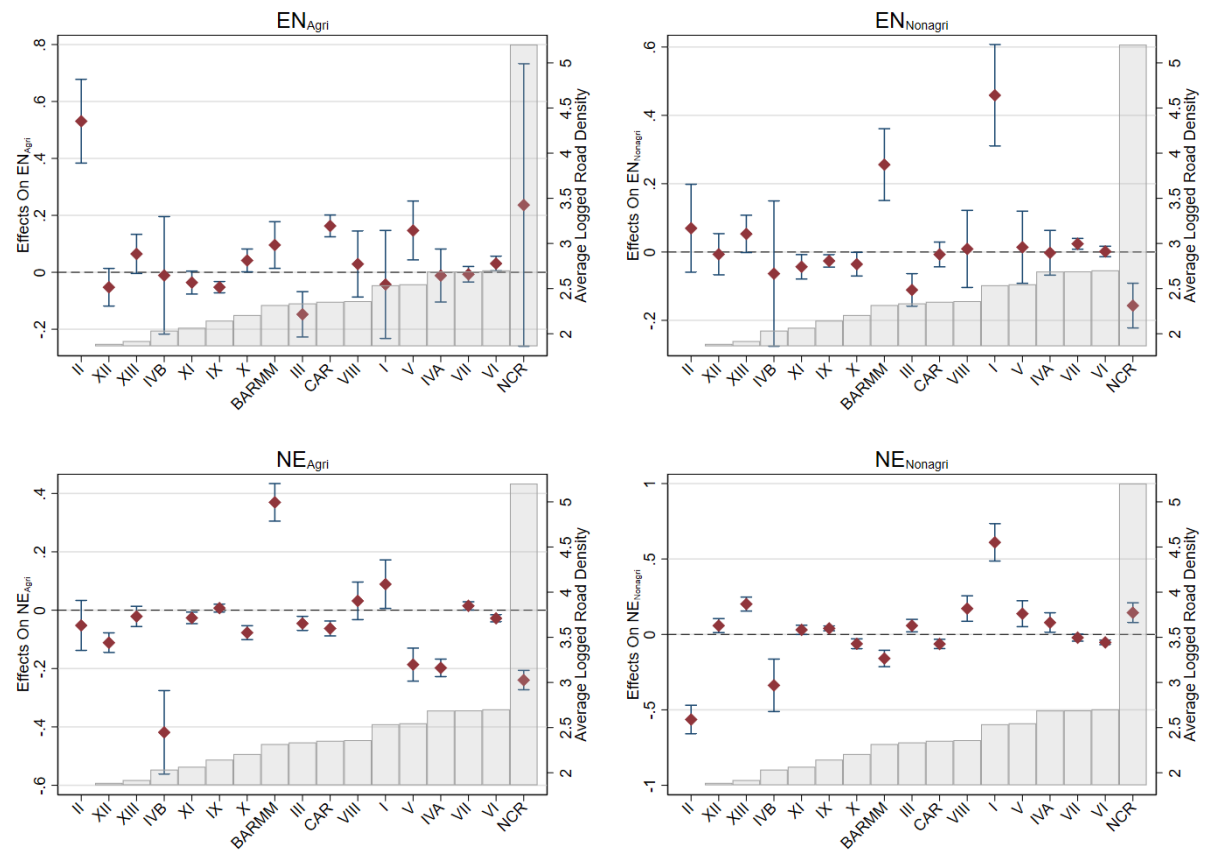

Source: Labor Force Survey, Philippine Statistics Authority; 2018 \& 2019 ATLAS, Department of Public Works and Highways. 


\section{CONCLUSION}

In this paper, we set our path to examine the underlying reasons for the agricultural exodus that took place in the Philippines during the last 15 years. In the estimation of labor market transition rates using the Philippines LFS, we firstly illustrate that the shrinking agricultural employment can be summarized as a flow process transitioning from agriculture to non-agriculture; we show empirically that workers separate more from their agricultural jobs and increasingly direct their search effort to non-agriculture. Next, by applying both the theoretical and empirical frameworks, we find evidence that some 'push' factors, namely, widening wage differentials, increasing labor market efficiency, and expanding road density in the Philippines are significantly correlated with employment outflows from agriculture, whilst the 'pull' factors, i.e., lack of high school and college education attainment and agricultural clusters, are associated with dampening the process. Furthermore, we estimate the economic significance of each proposed factor and find that in contrast to the traditional view, increasing wage differentials do not explain much of the agricultural exodus; instead, measures related to enhancing the worker's ability to freely switch industries exert more influence on their industry switching decision. In particular, we show that even high school education can add significantly more to the exodus through raising agricultural worker's job separation margin substantially. In addition to that, when college education is undertaken, employment outflows from agriculture to non-agriculture could be further amplified because workers can find and hold on to non-agricultural jobs more easily. Improving transport also plays a more economically significant role in driving intersectoral labor reallocations, as not only does higher road density reduce job finding in agriculture by a wide margin, but also it boosts job finding in non-agriculture significantly.

As previously indicated, our empirical study only selects a non-exhaustive list of factors based on the discipline provided by the model and estimates their correlation with the observed evolution in the labor market transition rates. Although our selection is restricted by the availability of data, we believe that the augmented theoretical framework could offer a more comprehensive view of what the 'push' and 'pull' factors are in general, and more importantly, through what mechanism these factors give rise to increasing employment outflows from agriculture to non-agriculture. In addition, the empirical framework could be easily extended to account for other influential factors once their data become available. Two notable examples include the land reform progress in the Philippines (Adamopoulos and Restuccia, 2020) and climate change (Rosegrant et al., 2016), both of which have the potential to affect agricultural productivity and hence the pace of employment outflows from agriculture. We leave these extensions for future endeavors. 


\section{APPENDIX I. THEORETICAL MODEL}

The goal of this section is to build a tractable model of the labor market capturing the conditions workers face when choosing employment status and industry. For simplicity, the model includes only two labor force statuses: employment $(e)$ and non-employment $(n)$; and two types of industries: agriculture $(A)$ and non-agriculture $(N A)$. To capture the empirical observation that job openings and job seekers simultaneously exist, we build a two-market random search model where labor market frictions prevent openings and job seekers from perfectly matching up. The model is motivated by the work of Den Haan et al. (2005) and Fujita (2018). We use the model to study the job separation and finding behaviors by agricultural workers, and consider the potential mechanisms contributing to the shrinking employment in agriculture. In what follows, we suppress the time indices until they become necessary for clarity.

\section{A. Environment}

The economy is populated by a unit mass of risk-neutral workers and an infinite mass of identical and infinitely lived firms. Each worker is endowed with one unit of labor, while each firm can hire at most one worker each time. When the job position is filled, the match produces output according to the following production function:

$$
y_{j}\left(x_{j}\right)=x_{j}, j \in\{A, N A\}
$$

where $x_{j}$ is the industry-specific idiosyncratic productivity. When the match is first formed, it draws its idiosyncratic productivity from $G_{j}\left(x_{j}\right)$ with support $(0, \infty)$.

There are two separate matching markets for each type of industry and workers participate in the matching market for their type while looking for a job. For industry $j$, the matching process between workers and firms is formally depicted by the existence of a constant returns to scale matching function:

$$
m_{j}\left(n_{j}, v_{j}\right)=\bar{m}_{j} n_{j}^{\alpha_{j}} v_{j}^{1-\alpha_{j}}
$$

where $\bar{m}_{j}$ stands for matching efficiency, $\alpha_{j}$ for the elasticity of the matching function with respect to non-employment, $n_{j}$ for the measure of the non-employed, and $v_{j}$ for the measure of vacancies. Let $\theta_{j} \equiv \frac{v_{j}}{n_{j}}$ denote labor market tightness. The job meeting rate can be written as $f_{j}\left(\theta_{j}\right) \equiv \frac{m_{j}}{n_{j}}=\bar{m}_{j} \theta_{j}^{1-\alpha_{j}}$, whereas the vacancy meeting rate is defined by $q_{j}\left(\theta_{j}\right) \equiv \frac{m_{j}}{v_{j}}=\bar{m}_{j} \theta_{j}^{-\alpha_{j}}$. The job and vacancy meeting rates satisfy the standard relationship $f_{j}\left(\theta_{j}\right)=q_{j}\left(\theta_{j}\right) \theta_{j}$.

We assume that workers face several possibilities in each period: firstly, both types of employed workers face the possibility that their productivities switch to a new level. The switch occurs 
with probability $\lambda$. When it occurs, the new productivity is drawn from $G_{j}($.$) . Each match can be$ endogenously terminated when the new productivity is too low. Secondly, workers switch industries with an exogenous probability, $1-\gamma_{j} .{ }^{16}$ Employed workers take into account the switching probability when deciding whether or not to endogenously separate, whilst non-employed workers consider it when deciding whether or not to remain in the same industry.

\section{B. Value Functions}

\section{Workers}

For industry $j \in\{A, N A\}$, let $W_{j}\left(x_{j}\right)$ denote the value of the $j$-type employed worker, written as:

$$
\begin{aligned}
W_{j}\left(x_{j}\right)=w_{j}\left(x_{j}\right)+\beta & (1-\lambda) W_{j}\left(x_{j}\right) \\
& \left.+\lambda \mathbb{E}_{x_{j}^{\prime}}\left\{\max \left[W_{j}\left(x_{j}^{\prime}\right), \gamma_{j} N_{j}+\left(1-\gamma_{j}\right) N_{\neg j}\right]\right\}\right),
\end{aligned}
$$

where $w_{j}\left(x_{j}\right)$ is the current-period wage, $\beta$ is the discount factor, $x_{j}^{\prime}$ is the productivity of this match in the next period, $N_{j}$ is the value of the $j$-type non-employed worker, and $N_{\neg j}$ is the value of the non-employed worker in the other industry. The present value of being an employed worker in industry $j$ is the earned wage $w_{j}$ plus the continuation value. With probability $1-\lambda$, the worker continues its employment as productivity stays the same. With probability $\lambda$, productivity switches, and the worker decides whether or not to endogenously separate. The max operator in Equation (3) characterizes the optimal continuation/separation decision. Conditional on separation, with probability $\gamma_{j}$, the worker becomes non-employed in the current industry; with probability $1-\gamma_{j}$, the worker switches to the other industry and searches for jobs there. Note that we do not model job-to-job transitions in the current setting as in the LFS, job-to-job transitions only represent a small proportion of the flows between $e_{A}$ and $e_{N A}(2.4 \%$ and $1 \%$ for agricultural and non-agricultural workers respectively).

The value of the $j$-type non-employed worker is given by:

$$
\begin{gathered}
N_{j}=b_{j}+\beta\left(f_{j}\left(\theta_{j}\right) \mathbb{E}_{x_{j}^{\prime}}\left\{\max \left[W_{j}\left(x_{j}^{\prime}\right), \gamma_{j} N_{j}+\left(1-\gamma_{j}\right) N_{\neg j}\right]\right\}\right. \\
\left.+\left(1-f_{j}\left(\theta_{j}\right)\right)\left[\gamma_{j} N_{j}+\left(1-\gamma_{j}\right) N_{\neg j}\right]\right),
\end{gathered}
$$

\footnotetext{
${ }^{16}$ To model the worker's industry switching behavior, we could apply an endogenous mechanism, e.g., assuming that workers draw some idiosyncratic industry-specific taste shocks which impact their switching decision (e.g., Artuç et al. (2010), Kennan and Walker (2011), and Pilossoph (2014)). However, we opt for the exogenous setting because it significantly reduces non-necessary analytical complexities without sacrificing any insight when compared to the endogenous counterpart.
} 
where $b_{j}$ is the flow outside value for the worker and $f_{j}\left(\theta_{j}\right)$ is the job meeting rate in industry $j$. A non-employed $j$-type worker earns a current period return of $b_{j}$, plus the expected continuation value. With probability $f_{j}\left(\theta_{j}\right)$, the worker meets a job and then decides whether to separate. Again, the max operator characterizes the optimal continuation/separation decision. With probability $1-f_{j}\left(\theta_{j}\right)$, the worker does not meet a job and continues to remain non-employed in the current industry with probability $\gamma_{j}$.

\section{Jobs}

For industry $j \in\{A, N A\}$, the job position filled with an employed worker embodies the following value:

$$
J_{j}\left(x_{j}\right)=x_{j}-w_{j}\left(x_{j}\right)+\beta\left\{(1-\lambda) J_{j}\left(x_{j}\right)+\lambda \mathbb{E}_{x_{j}^{\prime}}\left[\max \left(J_{j}\left(x_{j}^{\prime}\right), V_{j}\right)\right]\right\}
$$

where $V_{j}$ is the value of the unfilled position and the max operator characterizes the match continuation/destruction decision. The firm earns $x_{j}$, but must pay the worker a wage $w_{j}$. With probability $1-\lambda$, the employment continues as productivity stays the same. With probability $\lambda$, productivity switches. It may be too low and thus the match may be rejected. The firm then starts the next period with an unfilled position, which has value equal to:

$$
V_{j}=-c_{j}+\beta\left\{q_{j}\left(\theta_{j}\right) \mathbb{E}_{x_{j}^{\prime}}\left[\max \left(J_{j}\left(x_{j}^{\prime}\right), V_{j}\right)\right]+\left(1-q_{j}\left(\theta_{j}\right) V_{j}\right\}\right.
$$

where $c_{j}$ is the per period vacancy posting cost and $q_{j}\left(\theta_{j}\right)$ is the vacancy meeting rate. For simplicity, we assume free entry into the matching market that drives the value of the unfilled position to zero and thus the following job creation condition holds:

$$
\frac{c_{j}}{\beta q_{j}\left(\theta_{j}\right)}=\mathbb{E}_{x_{j}^{\prime}}\left[\max \left(J_{j}\left(x_{j}^{\prime}\right), 0\right)\right] .
$$

\section{Surplus Sharing and Separation Decision}

When the two parties meet, they either enter into an agreement, or they both revert to their outside options. The outside option of the worker is to either remain unmatched in the current industry or to switch to the other industry. The outside option of the firm is to remain unmatched and wait for another worker. The surplus of the match over the parties' outside options is split via generalized Nash bargaining.

When the employment relationship continues, each match in industry $j \in\{A, N A\}$ enjoys the 
surplus:

$$
S_{j}\left(x_{j}\right)=J_{j}\left(x_{j}\right)+W_{j}\left(x_{j}\right)-\left[\gamma_{j} N_{j}+\left(1-\gamma_{j}\right) N_{\neg j}\right]
$$

The worker takes a constant fraction, denoted as $\eta \in(0,1)$, of the total surplus and the firm takes the rest $1-\eta$, i.e., $\eta J_{j}\left(x_{j}\right)=(1-\eta)\left\{W_{j}\left(x_{j}\right)-\left[\gamma_{j} N_{j}+\left(1-\gamma_{j}\right) N_{\neg j}\right]\right\}$. Given this rule, the worker and the firm agree on the continuation/separation decision. Since $J_{j}\left(x_{j}\right)+W_{j}\left(x_{j}\right)$ is increasing in $x_{j}$, there exists a cutoff productivity $\underline{x}_{j}$ below (above) which both sides choose to sever (continue) the employment relationship; at $\underline{x}_{j}$,

$$
S_{j}\left(\underline{x}_{j}\right)=0
$$

\section{Partial Equilibrium in the Agricultural Labor Market}

Having defined the value functions and separation decisions, we turn to characterize the partial equilibrium in the agricultural labor market. We derive a positively-sloped job separation curve and a negatively-sloped job creation curve in a plane comprised of reservation productivity $\underline{x}_{A}$ and labor market tightness $\theta_{A}$. We use the framework to illustrate how in theory the 'push' and 'pull' factors in general affect the job separation and finding rates in the agricultural industry.

\section{Job Separation}

For simplicity, we define the expected surplus as $\mathbb{E} S_{j}\left(x_{j}^{\prime}\right) \equiv \int_{\underline{x}_{j}}^{\infty} S_{j}\left(x_{j}^{\prime}\right) d G_{j}\left(x_{j}^{\prime}\right)$ for $j \in\{A, N A\}$. Combining Equations (3), (4), and (5), the evolution of the surplus for the $A$-type match is given by:

$$
\begin{aligned}
S_{A}\left(x_{A}\right)=x_{A} & -\left[\gamma_{A} b_{A}+\left(1-\gamma_{A}\right) b_{N A}\right]+\beta\left[(1-\lambda) S_{A}\left(x_{A}\right)+\lambda \mathbb{E} S_{A}\left(x_{A}^{\prime}\right)\right] \\
& -\beta \eta\left[\gamma_{A} f_{A}\left(\theta_{A}\right) \mathbb{E} S_{A}\left(x_{A}^{\prime}\right)+\left(1-\gamma_{A}\right) f_{N A}\left(\theta_{N A}\right) \mathbb{E} S_{N A}\left(x_{N A}^{\prime}\right)\right] \\
& -\beta\left(1-\gamma_{A}\right)\left(1-\gamma_{A}-\gamma_{N A}\right)\left(N_{A}-N_{N A}\right),
\end{aligned}
$$

where the difference in non-employment values, $N_{A}-N_{N A}$, is given by:

$$
N_{A}-N_{N A}=\frac{b_{A}-b_{N A}+\beta \eta\left(f_{A}\left(\theta_{A}\right) \mathbb{E} S_{A}\left(x_{A}^{\prime}\right)-f_{N A}\left(\theta_{N A}\right) \mathbb{E} S_{N A}\left(x_{N A}^{\prime}\right)\right)}{1+\beta\left(1-\gamma_{A}-\gamma_{N A}\right)} .
$$


Evaluating Equation (8) at $\underline{x}_{A}$ yields the job separation condition in the agricultural labor market:

$$
\begin{aligned}
0 & =\gamma_{A} b_{A}+\left(1-\gamma_{A}\right) b_{N A}+\frac{\beta\left(1-\gamma_{A}\right)\left(1-\gamma_{A}-\gamma_{N A}\right)}{1+\beta\left(1-\gamma_{A}-\gamma_{N A}\right)}\left(b_{A}-b_{N A}\right) \\
& -\beta \lambda \mathbb{E} S_{A}\left(x_{A}^{\prime}\right)+\beta \eta\left[\gamma_{A} f_{A}\left(\theta_{A}\right) \mathbb{E} S_{A}\left(x_{A}^{\prime}\right)+\left(1-\gamma_{A}\right) f_{N A}\left(\theta_{N A}\right) \mathbb{E} S_{N A}\left(x_{N A}^{\prime}\right)\right] \\
& +\beta\left(1-\gamma_{A}\right)\left(1-\gamma_{A}-\gamma_{N A}\right) \frac{\beta \eta\left(f_{A}\left(\theta_{A}\right) \mathbb{E} S_{A}\left(x_{A}^{\prime}\right)-f_{N A}\left(\theta_{N A}\right) \mathbb{E} S_{N A}\left(x_{N A}^{\prime}\right)\right)}{1+\beta\left(1-\gamma_{A}-\gamma_{N A}\right)}-\underline{x}_{A} .
\end{aligned}
$$

Next, we add Equation (9) to Equation (8) and derive the surplus for the $A$-type match:

$$
S_{A}\left(x_{A}\right)=\frac{x_{A}-\underline{x}_{A}}{1-\beta(1-\lambda)}
$$

By further assuming idiosyncratic productivity $x_{A}$ is log-normally distributed with mean $\bar{x}_{A}$ and standard deviation $\sigma$, we can write the integral associated with truncated log-normal distribution in $\mathbb{E} S_{A}\left(x_{A}^{\prime}\right)$ as:

$$
\begin{aligned}
\mathbb{E} S_{A}\left(x_{A}^{\prime}\right) & \equiv \int_{\underline{x}_{A}}^{\infty} \frac{x_{A}^{\prime}-\underline{x}_{A}}{1-\beta(1-\lambda)} d G_{A}\left(x_{A}^{\prime}\right) \\
& =\frac{1}{1-\beta(1-\lambda)} \int_{\underline{x}_{A}}^{\infty} \frac{1}{\sigma \sqrt{2 \pi}} e^{-\frac{1}{2 \sigma^{2}}\left(\log \left(x_{A}^{\prime}\right)-\bar{x}_{A}\right)^{2}} d x_{A}^{\prime}-\frac{\underline{x}_{A}}{1-\beta(1-\lambda)}\left(1-G_{A}\left(\underline{x}_{A}\right)\right) .
\end{aligned}
$$

Define $z \equiv \frac{\log \left(x_{A}^{\prime}\right)-\left(\bar{x}_{A}+\sigma^{2}\right)}{\sigma}$. Using the substitution, $x_{A}^{\prime}=e^{\bar{x}_{A}+\sigma^{2}} e^{\sigma z}$, and by change of variables, we derive the expected surplus for A-type match as:

$$
\begin{aligned}
\mathbb{E} S_{A}\left(x_{A}^{\prime}\right)= & \frac{1}{1-\beta(1-\lambda)} e^{\bar{x}_{A}+\frac{1}{2} \sigma^{2}}\left\{1-\Phi\left[\frac{\log \left(\underline{x}_{A}\right)-\left(\bar{x}_{A}+\sigma^{2}\right)}{\sigma}\right]\right\} \\
& -\frac{\underline{x}_{A}}{1-\beta(1-\lambda)}\left(1-G_{A}\left(\underline{x}_{A}\right)\right),
\end{aligned}
$$

where $\Phi($.$) and G_{A}($.$) represent the standard normal and log-normal cumulative distribution$ functions respectively. As such, we apply the implicit function theorem and summarize the relationship between reservation productivity $\underline{x}_{A}$ and tightness measure $\theta_{A}$ that is embedded in the job separation condition in the following proposition:

Proposition 1. Define the job separation condition $F: \mathbb{R}^{2} \rightarrow \mathbb{R}$ as in Equation (9). Assuming the existence of a partial equilibrium such that a combination $\left(\underline{x}_{A, 0}, \theta_{A, 0}\right) \in \mathbb{R}^{2}$ yields $F\left(\underline{x}_{A, 0}, \theta_{A, 0}\right)=0$ and some calibration such that $\frac{\partial F}{\partial \underline{x}_{A}}\left(\underline{x}_{A, 0}, \theta_{A, 0}\right) \neq 0$,

$$
\frac{d \underline{x}_{A}}{d \theta_{A}}\left(\underline{x}_{A, 0}, \theta_{A, 0}\right)>0
$$


Proof. Given the stated assumptions, by the implicit function theorem, there is a neighborhood of $\left(\underline{x}_{A, 0}, \theta_{A, 0}\right)$ such that whenever $\theta_{A}$ is sufficiently close to $\theta_{A, 0}$, there is a unique $\underline{x}_{A}$ so that $F\left(\underline{x}_{A}, \theta_{A}\right)=0$. This assignment makes $\underline{x}_{A}$ a continuous function of $\theta_{A}$. As such, applying implicit differentiation to Equation (9) around $\left(\underline{x}_{A, 0}, \theta_{A, 0}\right)$ yields:

$$
\frac{d \underline{x}_{A}}{d \theta_{A}}=-\frac{\partial F / \partial \theta_{A}}{\partial F / \partial \underline{x}_{A}}
$$

In terms of $\frac{\partial F}{\partial \theta_{A}}$, we derive that:

$$
\frac{\partial F}{\partial \theta_{A}}=\frac{\gamma_{A}(1-\beta)+\beta\left(1-\gamma_{N A}\right)}{1+\beta\left(1-\gamma_{A}-\gamma_{N A}\right)} \beta \eta \mathbb{E} S_{A}\left(x_{A}^{\prime}\right)\left(1-\alpha_{A}\right) \bar{m}_{A} \theta_{A}^{-\alpha_{A}}>0
$$

for $\theta_{A} \in(0, \infty)$. On the other hand, $\frac{\partial F}{\partial \underline{x}_{A}}$ is written as:

$$
\frac{\partial F}{\partial \underline{x}_{A}}=\left[-\beta \lambda+\beta \eta f_{A}\left(\theta_{A}\right) \frac{\gamma_{A}+\beta\left(1-\gamma_{A}-\gamma_{N A}\right)}{1+\beta\left(1-\gamma_{A}-\gamma_{N A}\right)}\right] \frac{\partial \mathbb{E} S_{A}\left(x_{A}^{\prime}\right)}{\partial \underline{x}_{A}}-1
$$

Given Equation (10), we derive that $\frac{\partial \mathbb{E} S_{A}\left(x_{A}^{\prime}\right)}{\partial \underline{x}_{A}}=-\frac{1-G_{A}\left(\underline{x}_{A}\right)}{1-\beta(1-\lambda)}$. Replacing $\frac{\partial \mathbb{E} S_{A}\left(x_{A}^{\prime}\right)}{\partial \underline{x}_{A}}$ with this expression yields:

$$
\frac{\partial F}{\partial \underline{x}_{A}}=\left[\beta \lambda-\beta \eta f_{A}\left(\theta_{A}\right) \frac{\gamma_{A}+\beta\left(1-\gamma_{A}-\gamma_{N A}\right)}{1+\beta\left(1-\gamma_{A}-\gamma_{N A}\right)}\right] \frac{1-G_{A}\left(\underline{x}_{A}\right)}{1-\beta(1-\lambda)}-1 .
$$

Clearly the partial derivative $\frac{\partial F}{\partial \underline{x}_{A}}$ depends on the values of $\left(\underline{x}_{A}, \theta_{A}\right)$. However, taking into account that $\frac{\partial f_{A}\left(\theta_{A}\right)}{\partial \theta_{A}}>0$ and $\frac{\partial G_{A}\left(\underline{x}_{A}\right)}{\partial \underline{x}_{A}}>0$, we summarize its value by considering its two limits:

1. $\theta_{A} \rightarrow 0$ : it implies $f_{A}\left(\theta_{A}\right) \rightarrow 0$, and the partial derivative has an upper limit as:

$$
\frac{\partial F}{\partial \underline{x}_{A}} \rightarrow \frac{-\beta \lambda G_{A}\left(\underline{x}_{A}\right)-(1-\beta)}{1-\beta(1-\lambda)}<0,
$$

for any $\underline{x}_{A} \in(0, \infty)$ such that $G_{A}\left(\underline{x}_{A}\right) \in(0,1)$;

2. $\theta_{A} \rightarrow \infty$ : it implies $f_{A}\left(\theta_{A}\right) \rightarrow \infty$, and the partial derivative has a lower limit as:

$$
\frac{\partial F}{\partial \underline{x}_{A}} \rightarrow-\infty<0
$$

for any $\underline{x}_{A} \in(0, \infty)$ such that $G_{A}\left(\underline{x}_{A}\right) \in(0,1)$.

Therefore, we conclude that:

$$
\frac{\partial F}{\partial \underline{x}_{A}}<0,
$$


and combining it with Equations (11) and (12) gives:

$$
\frac{d \underline{x}_{A}}{d \theta_{A}}>0
$$

\section{Job Creation}

As given by Equation (6), the job creation condition illustrates that in equilibrium, the marginal benefit of posting a vacancy for a firm, that is its share of the expected surplus for a match, must equal the marginal cost which directly links to the vacancy posting cost and the easiness of meeting a worker. The job creation condition in the agricultural labor market can therefore be rewritten as:

$$
0=(1-\eta) \mathbb{E} S_{A}\left(x_{A}^{\prime}\right)-\frac{c_{A}}{\beta q_{A}\left(\theta_{A}\right)},
$$

from which we summarize the relationship between reservation productivity $\underline{x}_{A}$ and labor market tightness $\theta_{A}$ in the following proposition:

Proposition 2. Define the job creation condition $H: \mathbb{R}^{2} \rightarrow \mathbb{R}$ as in Equation (14). Assuming the existence of a partial equilibrium such that a combination $\left(\underline{x}_{A, 0}, \theta_{A, 0}\right) \in \mathbb{R}^{2}$ yields $H\left(\underline{x}_{A, 0}, \theta_{A, 0}\right)=$ 0 and some calibration such that $\frac{\partial H}{\partial \underline{x}_{A}}\left(\underline{x}_{A, 0}, \theta_{A, 0}\right) \neq 0$,

$$
\frac{d \underline{x}_{A}}{d \theta_{A}}\left(\underline{x}_{A, 0}, \theta_{A, 0}\right)<0 .
$$

Proof. Similar to Proposition 1, given the stated assumptions, $\underline{x}_{A}$ is a continuous function of $\theta_{A}$, and applying implicit differentiation yields $\frac{d \underline{x}_{A}}{d \theta_{A}}=-\frac{\partial H / \partial \theta_{A}}{\partial H / \partial \underline{x}_{A}}$. The partial derivative $\frac{\partial H}{\partial \theta_{A}}$ is calculated as:

$$
\frac{\partial H}{\partial \theta_{A}}=-\frac{c_{A}}{\beta \bar{m}_{A}} \alpha_{A} \theta_{A}^{\alpha_{A}-1}<0
$$

for $\theta_{A} \in(0, \infty)$, whereas the partial derivative $\frac{\partial H}{\partial \underline{x}_{A}}$ is written as:

$$
\frac{\partial H}{\partial \underline{x}_{A}}=-\frac{(1-\eta)\left(1-G_{A}\left(\underline{x}_{A}\right)\right)}{1-\beta(1-\lambda)}<0,
$$

for $\underline{x}_{A} \in(0, \infty)$. Consequently, we derive that $\frac{d \underline{x}_{A}}{d \theta_{A}}<0$.

As shown in Figure 4, there exist a positively-sloped job separation ( $J S$ ) curve and a negativelysloped job creation $(J C)$ curve in the $\left(\underline{x}_{A}, \theta_{A}\right)$ plane. The intersection, $\left(\underline{x}_{A, 0}, \theta_{A, 0}\right)$, marks the partial equilibrium in the agricultural labor market, and any shift in the job separation or creation 
curve due to changes in labor market conditions in either the agricultural or non-agricultural labor market will result in corresponding changes in $\left(\underline{x}_{A, 0}, \theta_{A, 0}\right)$, and thus affect the job separation and finding rates for agricultural workers.

\section{E. Comparative Statics}

In this section we will study the interactions between the $J S$ and $J C$ curves in Figure 4 so as to examine the influence of relevant factors on the job separation and finding in the agricultural industry, and how they contribute to or hinder the shrinking agricultural employment. In particular, we focus on two sets of factors - 'push' factors which capture incentives for workers to leave agriculture, and 'pull' factors which capture incentives for workers to remain in agriculture. Through comparative statics, we further illustrate that different 'push' ('pull') factors may stimulate (impede) the agricultural exodus through distinct channels. Lastly, this section complements our findings in Section II by including more analytical details.

\section{'Push' Factors}

First of all, let's consider an exogenous increase in mean productivity of the non-agricultural industry, $\bar{x}_{N A}$, such that the outside option for workers switching from agriculture to non-agriculture becomes more favorable, e.g., $f_{N A}\left(\theta_{N A}\right) \mathbb{E} S_{N A}\left(x_{N A}^{\prime}\right)$ rises. In order for the job separation condition (9) to hold, at given levels of $\theta_{A}$, the reservation productivity $\underline{x}_{A}$ will rise. ${ }^{17}$ This implies a leftward shift of the $J S$ curve to $J S^{\prime}$ as depicted in Figure 5. Assuming all else remain constant, at the new equilibrium where the $J S^{\prime}$ and $J C$ curves intersect, the reservation productivity increases to $\underline{x}_{A, 1}$ whilst the agricultural labor market tightness drops to $\theta_{A, 1}$. Since the separation rate in agriculture can be written as $\lambda G_{A}\left(\underline{x}_{A}\right)$ which is monotonically increasing in $\underline{x}_{A}$, higher $\underline{x}_{A}$ implies greater job separation in agriculture in equilibrium: since the outside option value for agricultural workers increases as a result of the increase in $\bar{x}_{N A}$, the surplus to be shared between agricultural workers and firms will decline, giving rise to that only the higher realizations of $x_{A}$ will be accepted. In terms of the job finding rate, it is given by $f_{A}\left(\theta_{A}\right)\left(1-G_{A}\left(\underline{x}_{A}\right)\right)$, which is monotonically increasing in $\theta_{A}$ and decreasing in $\underline{x}_{A}$. Therefore, the confluence of higher $\underline{x}_{A}$ and lower $\theta_{A}$ in equilibrium implies a lower job finding rate in agriculture: not only do agricultural workers become more 'picky' about job offers and decline more often, but also they face more difficulties in meeting a potential employer. In reality, such a productivity difference often manifests itself through widening wage differentials (as documented in Figure 10), therefore incen-

\footnotetext{
${ }^{17}$ Since the coefficient of the term $f_{N A}\left(\theta_{N A}\right) \mathbb{E} S_{N A}\left(x_{N A}^{\prime}\right), \frac{\beta \eta\left(1-\gamma_{A}\right)}{1+\beta\left(1-\gamma_{A}-\gamma_{N A}\right)}$, is positive in Equation (9), having known that $\frac{\partial F}{\partial \underline{x}_{A}}<0$, we derive that $\frac{d \underline{x}_{A}}{d\left(f_{N A}\left(\theta_{N A}\right) \mathbb{E} S_{N A}\left(x_{N A}^{\prime}\right)\right)}=-\frac{\partial F / \partial\left(f_{N A}\left(\theta_{N A}\right) \mathbb{E} S_{N A}\left(x_{N A}^{\prime}\right)\right)}{\partial F / \partial \underline{x}_{A}}>0$ while holding $\theta_{A}$ fixed.
} 
tivizing agricultural workers to move away from their land and search for non-agricultural jobs instead.

Similar dynamics can arise from an exogenous increase in the flow outside value for non-agricultural workers $b_{N A}$, or an exogenous increase in the matching efficiency in the non-agricultural industry $\bar{m}_{N A}$, as they both behave to raise the outside option value faced by agricultural workers. Lastly, it is noted the increasing productivity difference between agriculture and non-agriculture may also result from lower $\bar{x}_{A}$ instead of higher $\bar{x}_{N A}$, which in certain scenarios (see Figure 6 for an illustration) will lead to both the $J S$ and $J C$ curves shifting to the left, and yield similar outcomes to those with only the $J S$ curve shifting to the left.

In addition to the aforementioned 'push' factors, a boost to matching efficiency in the agricultural industry $\bar{m}_{A}$ may also lead to significant employment outflows from agriculture, even though the exact mechanism through which the outflows take place varies from the previous ones. Specifically, an exogenous increase in $\bar{m}_{A}$ triggers not only a leftward shift of the $J S$ curve, but also a rightward shift of $J C$ curve. ${ }^{18,19}$ The intuition is that the boost to matching efficiency in the agricultural industry not only enhances the outside option for its workers (as they can find jobs more easily), but also improves the ability of firms in filling their vacancies and encourages them to create more agricultural jobs. Graphically, in Figure 7, assuming that the shift in the $J C$ curve is relatively small (which often occurs when $\alpha_{A}$ is small at low levels of $\theta_{A}$ ), at the new equilibrium where $J S^{\prime \prime \prime}$ and $J C^{\prime \prime \prime}$ curves intersect, the reservation productivity increases to $\underline{x}_{A, 3}$ whilst the agricultural labor market tightness drops to $\theta_{A, 3}$. This leads to similar outcomes as in the other cases, namely, greater job separation but lower job finding probabilities in the agricultural industry. Therefore, given such model predictions, it is expected that better-functioning labor market and increasing measures to boost matching efficiency (e.g., improved transport infrastructure) will serve to promote agricultural employment outflows.

\section{'Pull' Factors}

Now we turn to the 'pull' factors and analyze how they influence the job separation and finding rates in agriculture. We start with an exogenous decrease in the flow outside value for agricultural workers, $b_{A}$. Holding all else constant, in order for the job separation condition (9) to hold, for given values of $\theta_{A}$, this time the reservation productivity $\underline{x}_{A}$ will fall. This implies a right-

\footnotetext{
${ }^{18}$ It can be shown from Equation (9) that the multiplicative terms before $f_{A}\left(\theta_{A}\right)$ write as $\frac{\gamma_{A}(1-\beta)+\beta\left(1-\gamma_{N A}\right)}{1+\beta\left(1-\gamma_{A}-\gamma_{N A}\right)} \beta \eta \mathbb{E} S_{A}\left(x_{A}^{\prime}\right)>0$. Therefore, given that $f_{A}\left(\theta_{A}\right) \equiv \bar{m}_{A} \theta_{A}^{1-\alpha_{A}}$, it implies at each $\underline{x}_{A}$ where Equation (9) holds, an increase in $\bar{m}_{A}$ results in a corresponding decline in $\theta_{A}$ such that the $J S$ curve shifts to the left.

${ }^{19}$ From Equation (14) we can clearly see that at each $\underline{x}_{A}$ where it holds, for an exogenous increase in $\bar{m}_{A}, \theta_{A}$ will rise accordingly, provided that $q_{A}\left(\theta_{A}\right) \equiv \bar{m}_{A} \theta_{A}^{-\alpha_{A}}$.
} 
ward shift of the $J S$ curve to $J S^{*}$ as depicted in Figure 8. As a result, at the new equilibrium where $J S^{*}$ and $J C$ curves intersect, the reservation productivity decreases to $\underline{x}_{A, 4}$ whilst the agricultural labor market tightness increases to $\theta_{A, 4}$; compared to the original equilibrium, the job separation rate falls whilst the job finding rate increases in the agricultural industry. ${ }^{20}$ The intuition is simple: the decrease in the agricultural worker's flow outside value enlarges the surplus to be shared, which then leads to that lower realizations of idiosyncratic productivities - which were previously rejected - are now accepted; in other words, workers become less 'picky' and become less likely to separate. In practice, the decrease in the flow outside value for agricultural workers is often associated with lack of education or skill depreciation, as they cannot satisfy the skill requirements for non-agricultural jobs and thus get stuck in agriculture. A similar situation can also occur when there is a significant agricultural cluster effect due to lock-ins.

Another 'pull' factor to note is the deteriorating bargaining power of agricultural workers in their wage negotiation, which may also arise in the case of obsolete skills or agricultural clusters. Yet, the mechanism through which the decrease in $\eta$ hinders agricultural exodus differs from that illustrated in Figure 8; it instead involves rightward shifts in both the $J S$ and $J C$ curves. ${ }^{21}$ The dynamics are shown in Figure 9, and the new equilibrium is where the $J S^{* *}$ and $J C^{* *}$ curves intersect, provided that the shift in the $J C$ curve is relatively small (which often occurs when $\alpha_{A}$ is large at high levels of $\theta_{A}$ ). The new equilibrium features lower job separation but higher job finding probabilities in the agricultural industry because on the one hand, the lower bargaining power of workers shrinks their share of the matching surplus and discourages job separation, while on the other hand, the resulting greater bargaining power of firms (i.e., $1-\eta$ ) increases their share of the matching surplus and promotes job creation. Hence, given the model predictions, it is expected that inadequate education and significant agricultural clusters will serve to dampen agricultural employment outflows.

\footnotetext{
${ }^{20}$ Again, in theory, similar dynamics can arise from an exogenous decrease in the flow outside value for nonagricultural workers $b_{N A}$ or an exogenous decrease in the matching efficiency in the non-agricultural industry $\bar{m}_{N A}$, as both of them behave to shrink the outside option value faced by agricultural workers. However, we rarely find empirical or anecdotal evidence supporting these two arguments in practice.

${ }^{21}$ First, the terms associated with $\eta$ in Equation (9) can be collected as $\eta\left\{\frac{\gamma_{A}(1-\beta)+\beta\left(1-\gamma_{N A}\right)}{1+\beta\left(1-\gamma_{A}-\gamma_{N A}\right)} \beta f_{A}\left(\theta_{A}\right) \mathbb{E} S_{A}\left(x_{A}^{\prime}\right)+\right.$ $\left.\frac{\left(1-\gamma_{A}\right)\left[(1-\beta)+\beta\left(\gamma_{A}+\gamma_{N A}\right)\right]}{1+\beta\left(1-\gamma_{A}-\gamma_{N A}\right)} \beta f_{N A}\left(\theta_{N A}\right) \mathbb{E} S_{N A}\left(x_{N A}^{\prime}\right)\right\}$. Therefore, at each $\underline{x}_{A}$ where Equation (9) holds, a reduction in $\eta$ will lead to a corresponding increase in $\theta_{A}$, holding all else constant. On the other hand, from Equation (14), it implies that at each $\underline{x}_{A}$ while the condition is satisfied, a reduction in $\eta$ will lead to a corresponding increase in $\theta_{A}$.
} 


\section{APPENDIX II. END BEHAVIORS OF THE $E N$ AND $N E$ RATES}

To explore on the extent to which our baseline regression results are affected by the nonconforming end behaviors of $E N$ and $N E$ rates as documented in Figures $3 \mathrm{a}$ and $3 \mathrm{~b}$, we apply two exercises, in which we add a time dummy indicating 2005Q2-2008Q1 and 2017Q1-2019Q4 respectively in the LPM of each labor market transition rate, and interact it with the proposed 'push' and 'pull' factors.

The estimated AMEs of each factor during different sample periods are presented in Tables II.1 and II.2. In Table II.1, we find that most results are robust, except that the AME of real wage differentials on $N E_{\text {Nonagri }}$ turns negative and highly significant during 2005Q2-2008Q1, which is in principle consistent with the stagnation of real wage differentials during the same period, as shown in Figure 10. On the other hand, in Table II.2, we find that the estimated effects of real wage differentials, labor market efficiency, high school and college education, and palay and corn production on the EN rates are robust in 2005Q2-2016Q4; however, increasing road density reduces job separations for both agricultural and non-agricultural workers, reflecting that road density may serve as a proxy for some other factor in the regression. The estimated effects of real wage differentials, labor market efficiency, high school, and college education on the $N E$ rate for agricultural workers are robust in the limited sample period; in contrast, only the estimated effects of road density and college education on the $N E$ rate for non-agricultural workers are robust in 2005Q2-2016Q4. Given the evidence, we conclude that most of the inconsistencies in results are associated with the behavior of $N E_{\text {Nonagri }}$ towards the end of the sample period, which may result from the implementation of the New Master Sample Design of the LFS starting in 2016Q2. 
Table II.1: AMEs in the LPM with time dummy representing 2005Q2-2008Q1

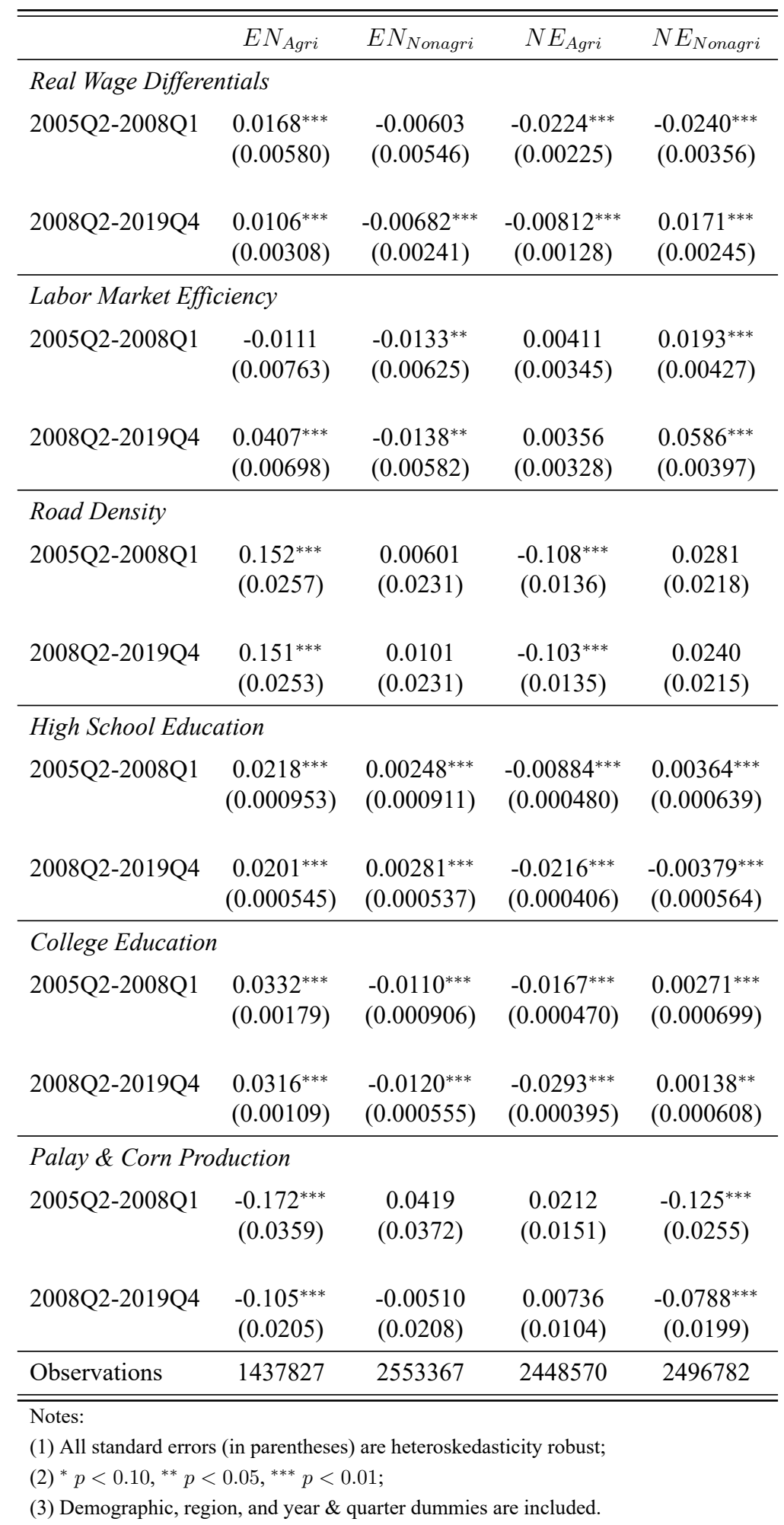

(CInternational Monetary Fund. Not for Redistribution 
Table II.2: AMEs in the LPM with time dummy representing 2017Q1-2019Q4

\begin{tabular}{|c|c|c|c|c|}
\hline & $E N_{\text {Agri }}$ & $E N_{\text {Nonagri }}$ & $N E_{\text {Agri }}$ & $N E_{\text {Nonagri }}$ \\
\hline \multicolumn{5}{|c|}{ Real Wage Differentials } \\
\hline 2005Q2-2016Q4 & $\begin{array}{l}0.0164^{* * *} \\
(0.00250)\end{array}$ & $\begin{array}{c}-0.000583 \\
(0.00224)\end{array}$ & $\begin{array}{c}-0.00456^{* * *} \\
(0.000818)\end{array}$ & $\begin{array}{c}-0.00452^{* * *} \\
(0.00160)\end{array}$ \\
\hline 2017Q1-2019Q4 & $\begin{array}{c}0.00609 \\
(0.00916)\end{array}$ & $\begin{array}{l}-0.00710 \\
(0.00552)\end{array}$ & $\begin{array}{c}0.00458 \\
(0.00363)\end{array}$ & $\begin{array}{l}0.0320^{* * *} \\
(0.00628)\end{array}$ \\
\hline \multicolumn{5}{|c|}{ Labor Market Efficiency } \\
\hline 2005Q2-2016Q4 & $\begin{array}{c}0.117^{*} \\
(0.0663)\end{array}$ & $\begin{array}{c}-0.160^{* * *} \\
(0.0381)\end{array}$ & $\begin{array}{c}-0.210^{* * *} \\
(0.0208)\end{array}$ & $\begin{array}{c}-0.272^{* * *} \\
(0.0462)\end{array}$ \\
\hline 2017Q1-2019Q4 & $\begin{array}{l}0.162^{* * *} \\
(0.0628)\end{array}$ & $\begin{array}{c}-0.119^{* * *} \\
(0.0345)\end{array}$ & $\begin{array}{c}-0.192^{* * *} \\
(0.0193)\end{array}$ & $\begin{array}{c}-0.191^{* * *} \\
(0.0428)\end{array}$ \\
\hline \multicolumn{5}{|l|}{ Road Density } \\
\hline 2005Q2-2016Q4 & $\begin{array}{c}-0.172^{* * *} \\
(0.0289)\end{array}$ & $\begin{array}{c}-0.0900^{* * *} \\
(0.0262)\end{array}$ & $\begin{array}{l}0.00491 \\
(0.0120)\end{array}$ & $\begin{array}{c}0.0656^{* * *} \\
(0.0174)\end{array}$ \\
\hline 2017Q1-2019Q4 & $\begin{array}{c}-3.583^{* * *} \\
(1.077)\end{array}$ & $\begin{array}{l}-1.252^{*} \\
(0.723)\end{array}$ & $\begin{array}{c}-0.0503 \\
(0.565)\end{array}$ & $\begin{array}{c}-1.552^{* *} \\
(0.739)\end{array}$ \\
\hline \multicolumn{5}{|c|}{ High School Education } \\
\hline 2005Q2-2016Q4 & $\begin{array}{c}0.0199^{* * *} \\
(0.000477)\end{array}$ & $\begin{array}{c}0.00328^{* * *} \\
(0.000467)\end{array}$ & $\begin{array}{c}-0.00761^{* * *} \\
(0.000255)\end{array}$ & $\begin{array}{l}0.00337^{* * *} \\
(0.000339)\end{array}$ \\
\hline 2017Q1-2019Q4 & $\begin{array}{l}0.0231^{* * *} \\
(0.00156)\end{array}$ & $\begin{array}{c}0.00100 \\
(0.00131)\end{array}$ & $\begin{array}{c}-0.0549^{* * *} \\
(0.00114)\end{array}$ & $\begin{array}{c}-0.0202^{* * *} \\
(0.00159)\end{array}$ \\
\hline \multicolumn{5}{|l|}{ College Education } \\
\hline 2005Q2-2016Q4 & $\begin{array}{c}0.0341^{* * *} \\
(0.000968)\end{array}$ & $\begin{array}{l}-0.0109^{* * *} \\
(0.000479)\end{array}$ & $\begin{array}{l}-0.0140^{* * *} \\
(0.000251)\end{array}$ & $\begin{array}{l}0.00185^{* * *} \\
(0.000367)\end{array}$ \\
\hline 2017Q1-2019Q4 & $\begin{array}{l}0.0225^{* * *} \\
(0.00278)\end{array}$ & $\begin{array}{c}-0.0151^{* * *} \\
(0.00135)\end{array}$ & $\begin{array}{c}-0.0694^{* * *} \\
(0.00114)\end{array}$ & $\begin{array}{c}0.00163 \\
(0.00179)\end{array}$ \\
\hline \multicolumn{5}{|c|}{ Palay \& Corn Production } \\
\hline 2005Q2-2016Q4 & $\begin{array}{c}-0.133^{* * *} \\
(0.0167)\end{array}$ & $\begin{array}{r}-0.00649 \\
(0.0163)\end{array}$ & $\begin{array}{c}0.00918 \\
(0.00651)\end{array}$ & $\begin{array}{c}-0.000699 \\
(0.0114)\end{array}$ \\
\hline 2017Q1-2019Q4 & $\begin{array}{l}-0.0402 \\
(0.0636)\end{array}$ & $\begin{array}{l}-0.0850 \\
(0.0587)\end{array}$ & $\begin{array}{l}-0.0514 \\
(0.0395)\end{array}$ & $\begin{array}{c}-0.339^{* * *} \\
(0.0722)\end{array}$ \\
\hline OObservations & 1437827 & 2553367 & 2448570 & 2496782 \\
\hline
\end{tabular}

Notes:

(1) All standard errors (in parentheses) are heteroskedasticity robust;

(2) ${ }^{*} p<0.10,{ }^{* *} p<0.05,{ }^{* * *} p<0.01$;

(3) Demographic, region, and year \& quarter dummies are included. 


\section{APPENDIX III. ADDITIONAL FIGURES AND TABLES}

Figure III.1: AMEs of college education, by region
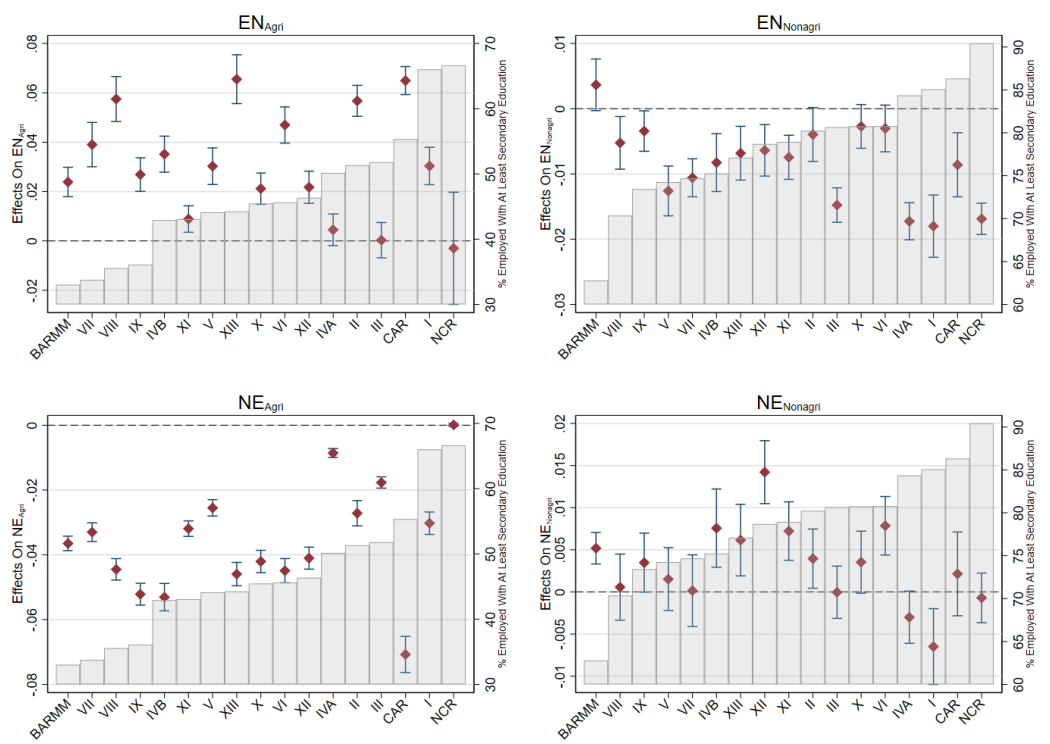

Source: Labor Force Survey, Philippine Statistics Authority.

Figure III.2: AMEs of college education, by age
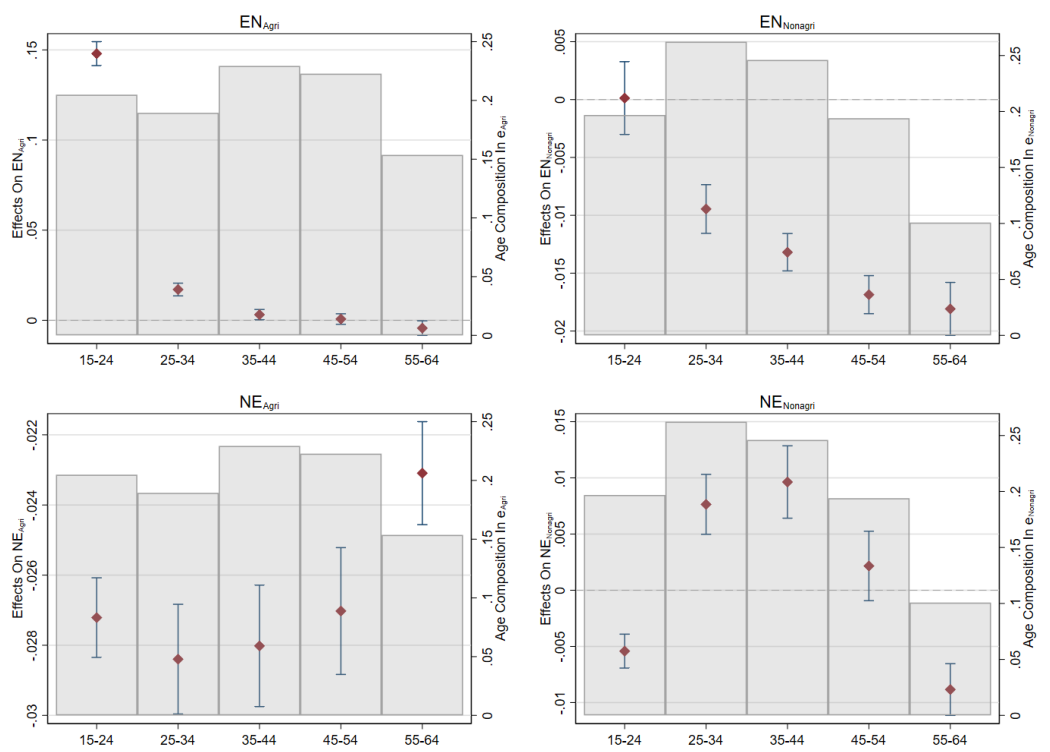

Source: Labor Force Survey, Philippine Statistics Authority. The underlying LPM includes interaction terms between college education dummy, region dummies, and age dummies. 
Figure III.3: AMEs of college education, by gender
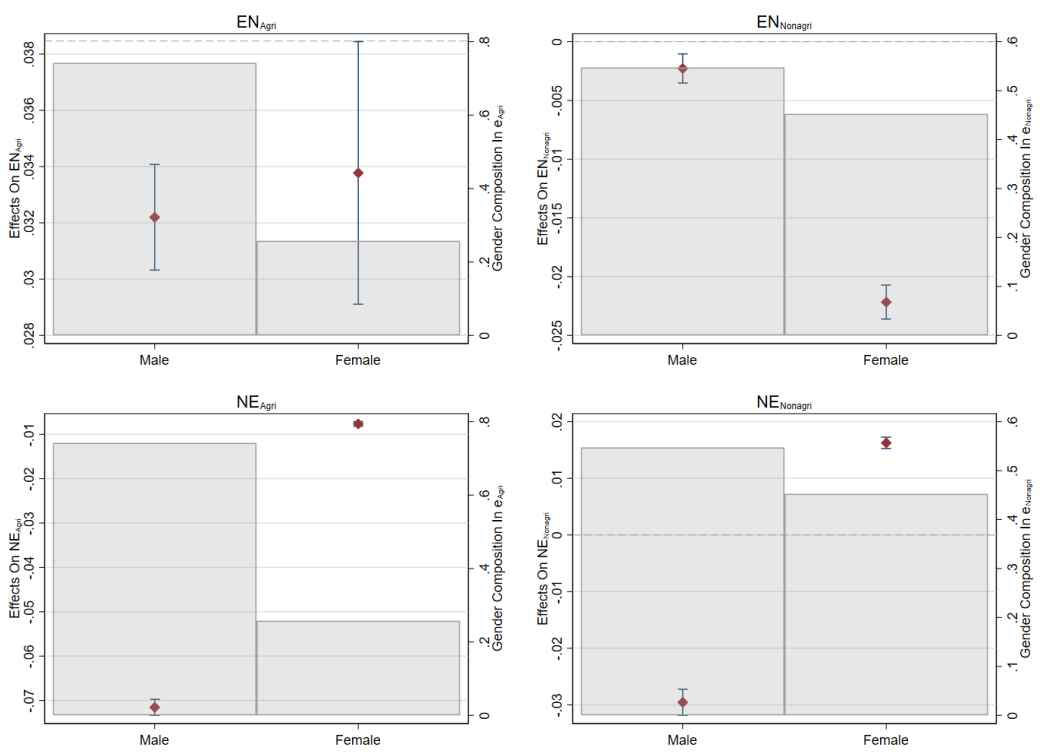

Source: Labor Force Survey, Philippine Statistics Authority. The underlying LPM includes interaction terms between college education dummy, region dummies, and gender dummies. 
Table III.1: AMEs in the LPM with clustered standard errors at the regional level

\begin{tabular}{lcccc}
\hline \hline & $E N_{\text {Agri }}$ & $E N_{\text {Nonagri }}$ & $N E_{\text {Agri }}$ & $N E_{\text {Nonagri }}$ \\
\hline 'Push' Factors & & & & \\
Real Wage Differentials & 0.00947 & -0.00572 & -0.00683 & 0.00631 \\
& $(0.00683)$ & $(0.00355)$ & $(0.00540)$ & $(0.0191)$ \\
& & & & \\
Labor Market Efficiency & 0.00675 & $-0.0175^{* * *}$ & -0.00174 & $0.0496^{* * *}$ \\
& $(0.00927)$ & $(0.00519)$ & $(0.00580)$ & $(0.00967)$ \\
& & & & \\
Road Density & 0.0487 & -0.0170 & -0.0768 & 0.0552 \\
& $(0.0985)$ & $(0.0654)$ & $(0.0889)$ & $(0.0968)$ \\
\hline 'Pull' Factors & & & & \\
High School Education & $0.0204^{* * *}$ & $0.00276^{* *}$ & $-0.0190^{* * *}$ & $-0.00237^{* *}$ \\
& $(0.00281)$ & $(0.000956)$ & $(0.00365)$ & $(0.00109)$ \\
College Education & $0.0319^{* * *}$ & $-0.0118^{* * *}$ & $-0.0267^{* * *}$ & 0.00173 \\
& $(0.00454)$ & $(0.00117)$ & $(0.00517)$ & $(0.00159)$ \\
Palay \& Corn Production & $-0.112^{*}$ & -0.0208 & 0.00976 & -0.0340 \\
& $(0.0583)$ & $(0.0243)$ & $(0.0530)$ & $(0.0689)$ \\
\hline \hline Observations & 1437827 & 2553367 & 2448570 & 2496782 \\
\hline \hline
\end{tabular}

Notes:

(1) All standard errors (in parentheses) are clustered at the regional level;

(2) ${ }^{*} p<0.10,{ }^{* *} p<0.05,{ }^{* * *} p<0.01$;

(3) Demographic, region, and year \& quarter dummies are included. 
Table III.2: AMEs of the proposed 'push' and 'pull' factors in a logit model

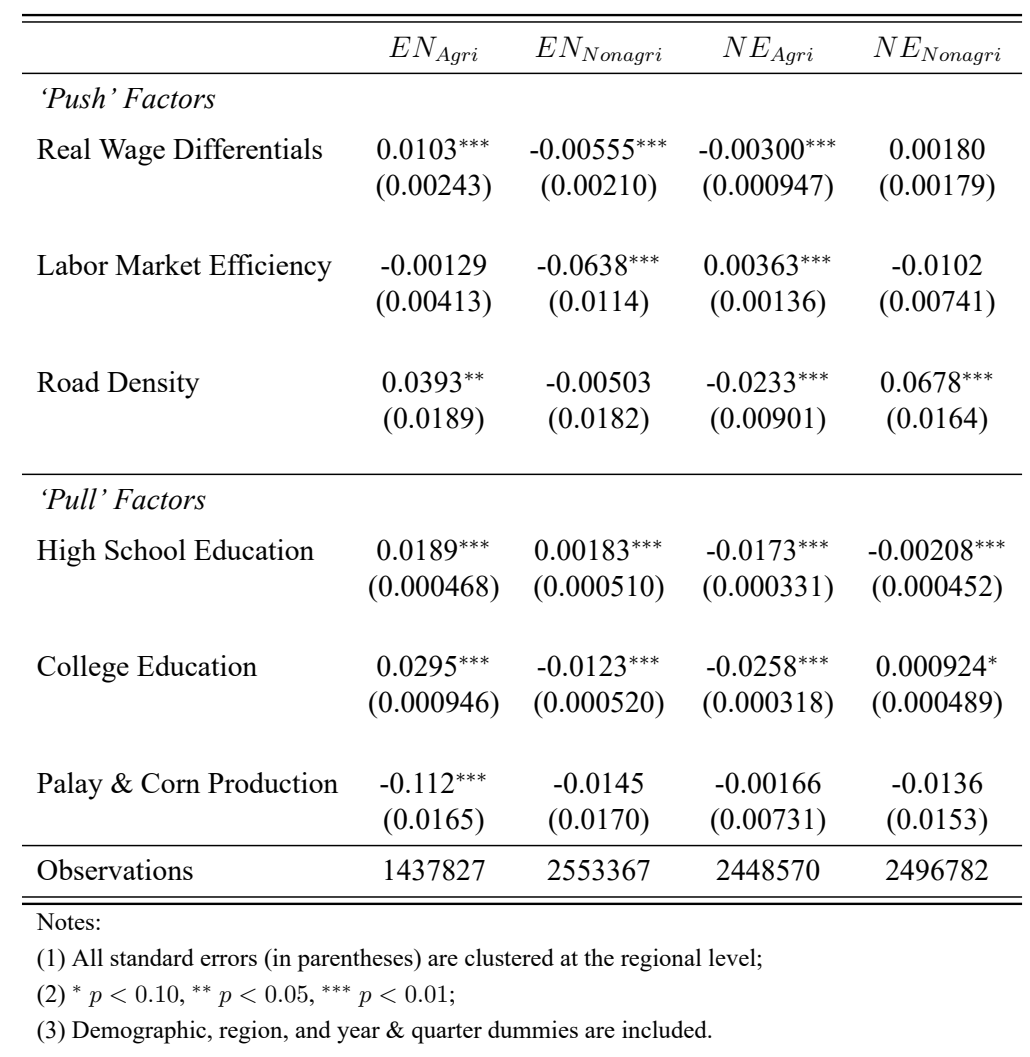




\section{REFERENCES}

T. Adamopoulos and D. Restuccia. Land reform and productivity: A quantitative analysis with micro data. American Economic Journal: Macroeconomics, 12(3):1-39, 2020.

E. Artuç, S. Chaudhuri, and J. McLaren. Trade shocks and labor adjustment: A structural empirical approach. American Economic Review, 100(3):1008-45, 2010.

M. Balgova. Leaping into the unknown? The role of job search in migration decisions. Unpublished Manuscript, 2020.

Š. Bojnec and L. Dries. Causes of Changes in Agricultural Employment in Slovenia: Evidence from Micro-data. Journal of Agricultural Economics, 56(3):399-416, 2005.

M. Bosch. Does unemployment insurance offer incentives to take jobs in the formal sector? IZA World of Labor, 2016.

T. Brenner and A. Gildner. The long-term implications of local industrial clusters. European Planning Studies, 14(9):1315-1328, 2006.

R. M. Briones. Characterization of agricultural workers in the Philippines. Technical report, PIDS Discussion Paper Series, 2017a.

R. M. Briones. Outlook for the Philippine economy and agro-industry to 2030: The role of productivity growth. Technical report, PIDS Discussion Paper Series, $2017 \mathrm{~b}$.

P. Bustos, J. Castro-Vincenzi, J. Monras, and J. Ponticelli. Industrialization without Innovation. Unpublished Manuscript, 2020.

A. C. Cameron and P. K. Trivedi. Microeconometrics: methods and applications. Cambridge university press, 2005.

L. S. Carvalho et al. Poverty and time preference. RAND Corporation Publications Department, Working Papers, 1:2010, 2010.

F. Caselli. Accounting for cross-country income differences. Handbook of economic growth, 1 : 679-741, 2005.

J. Cohen, P. Cohen, S. G. West, and L. S. Aiken. Applied multiple regression/correlation analysis for the behavioral sciences. Routledge, 2013.

W. J. Den Haan, C. Haefke, and G. Ramey. Turbulence and unemployment in a job matching model. Journal of the European Economic Association, 3(6):1360-1385, 2005. 
D. Donaldson. Railroads of the Raj: Estimating the impact of transportation infrastructure. American Economic Review, 108(4-5):899-934, 2018.

M. W. Elsby and M. D. Shapiro. Why does trend growth affect equilibrium employment? A new explanation of an old puzzle. American Economic Review, 102(4):1378-1413, 2012.

M. W. Elsby, R. Michaels, and G. Solon. The ins and outs of cyclical unemployment. American Economic Journal: Macroeconomics, 1(1):84-110, 2009.

European Commission. Modernising and simplifying the CAP. Background Document Economic challenges facing EU agriculture. Technical report, European Commission, DirectorateGeneeral for Agriculture and Rural Development, 2017.

J. Felipe, C. Bayudan-Dacuycuy, and M. Lanzafame. The Declining Share of Agricultural Employment in the People's Republic of China: How Fast? Asian Development Bank Economics Working Paper Series, (419), 2014.

K. Fuglie. 16 Productivity Growth and Technology Capital in the Global Agricultural Economy. Productivity Growth In Agriculture: An International Perspective, page 335, 2012.

K. Fuglie. Accounting for growth in global agriculture. Bio-Based And Applied Economics, 4(3): 201-234, 2015.

S. Fujita. Declining labor turnover and turbulence. Journal of Monetary Economics, 99:1-19, 2018.

M. Gervais, N. Jaimovich, H. E. Siu, and Y. Yedid-Levi. What should I be when I grow up? Occupations and unemployment over the life cycle. Journal of Monetary Economics, 83:54-70, 2016.

D. Gollin, D. Lagakos, and M. E. Waugh. The agricultural productivity gap. The Quarterly Journal of Economics, 129(2):939-993, 2014.

B. Herrendorf, R. Rogerson, and A. Valentinyi. Growth and structural transformation. In Handbook of Economic Growth, volume 2, pages 855-941. Elsevier, 2014.

International Monetary Fund. IV Chronic Unemployment in the Euro Area: Causes and Cures. Technical report, World Economic Outlook, International Monetary Fund, 1999.

C. Juhn, K. M. Murphy, R. H. Topel, J. L. Yellen, and M. N. Baily. Why has the natural rate of unemployment increased over time? Brookings Papers on Economic Activity, 1991(2):75-142, 1991. 
C. Juhn, K. M. Murphy, and R. H. Topel. Current unemployment, historically contemplated. Brookings Papers on Economic Activity, 2002(1):79-116, 2002.

J. Kennan and J. R. Walker. The effect of expected income on individual migration decisions. Econometrica, 79(1):211-251, 2011.

K. H. Koirala, A. Mishra, and S. Mohanty. Impact of land ownership on productivity and efficiency of rice farmers: The case of the Philippines. Land Use Policy, 50:371-378, 2016.

D. Lagakos and M. E. Waugh. Selection, agriculture, and cross-country productivity differences. American Economic Review, 103(2):948-80, 2013.

G. M. Llanto. The impact of infrastructure on agricultural productivity. Technical report, PIDS Discussion Paper Series, 2012.

K. Matsuyama. A simple model of sectoral adjustment. The Review of Economic Studies, 59(2): 375-387, 1992.

A. Maucorps, A. Münch, S. Brkanovic, B. Schuh, J. C. Dwyer, M. Vigani, A. Khafagy, M. Coto Sauras, P. Deschellette, A. Lopez, et al. The EU farming employment: current challenges and future prospects. 2019.

B. McCaig and N. Pavcnik. Moving out of agriculture: structural change in Vietnam. Technical report, National Bureau of Economic Research, 2013.

M. S. McMillan and D. Rodrik. Globalization, structural change and productivity growth. Technical report, National Bureau of Economic Research, 2011.

G. Menzio, I. A. Telyukova, and L. Visschers. Directed search over the life cycle. Review of Economic Dynamics, 19:38-62, 2016.

D. T. Mortensen and C. A. Pissarides. Job creation and job destruction in the theory of unemployment. The review of economic studies, 61(3):397-415, 1994.

Organisation for Economic Co-operation and Development. The OECD jobs study: Evidence and explanations. Technical report, Organisation for Economic Co-operation and Development, 1994.

I. Ostoj. Labor market efficiency as one of the pillars of the global competitiveness of an economy-conclusions for the labor market regimes of the EU countries. Journal of Economics \& Management, 20:80-92, 2015.

L. Pilossoph. Sectoral Shocks and Move Unemployment. Unpublished manuscript, 2014. 
R. Qian, M. K. Warwick, N. Diop, B. Hansl, K. T. G. Cruz, M. Bruckner, K. C. Chua, K. A. L. Enriquez, R. M. N. Galang, A. F. Garcia, et al. Growth and Productivity in the Philippines: Winning the Future. Technical report, The World Bank, 2018.

D. Restuccia, D. T. Yang, and X. Zhu. Agriculture and aggregate productivity: A quantitative cross-country analysis. Journal of monetary economics, 55(2):234-250, 2008.

M. Rizov and J. F. Swinnen. Human capital, market imperfections, and labor reallocation in transition. Journal of Comparative Economics, 32(4):745-774, 2004.

M. W. Rosegrant, N. Perez, A. Pradesha, and T. S. Thomas. The economywide impacts of climate change on Philippine agriculture. Technical report, International Food Policy Research Institute, 2016.

K. Schwab. The global competitiveness report 2018. Technical report, World Economic Forum, 2019.

R. Shimer. Reassessing the ins and outs of unemployment. Review of Economic Dynamics, 15 (2):127-148, 2012.

L. A. Sjaastad. The costs and returns of human migration. Journal of Political Economy, 70(5, Part 2):80-93, 1962.

R. G. Teruel and Y. Kuroda. Public infrastructure and productivity growth in Philippine agriculture, 1974-2000. Journal of Asian Economics, 16(3):555-576, 2005.

B. Tocco, A. Bailey, and S. Davidova. Determinants to leave agriculture and change occupational sector: Evidence from an enlarged EU. Technical report, 2013.

Y. Yang. Transport Infrastructure, City Productivity Growth and Sectoral Reallocation: Evidence from China. IMF Working Paper No. 18/276, 2018. 